Integrated Analysis and Design in Stochastic Optimization

by

George K. Maglaras

Thesis submitted to the Faculty of the

Virginia Polytechnic Institute and State University

in partial fulfillment of the requirements for the degree of

Master of Science

in

Aerospace and Ocean Engineering

APPROVED:

Nikolaidis, Chairman

R. T. Haftka

Owen F. Fughes

August, 1989

Blacksburg, Virginia 


\title{
Integrated Analysis and Design in Stochastic Optimization
}

by

\author{
George K. Maglaras \\ Efstratios Nikolaidis, Chairman \\ Aerospace and Ocean Engineering
}

(ABSTRACT)

When structural optimization is performed via an iterative solution technique, it is possible to integrate the analysis and design iterations, in an integrated analysis and design procedure. The present work seeks to apply an integrated analysis and design approach in reliability based optimization, when a safety index approach is used.

Two variants of the new approach are presented. Both of them are based on partially converged solution of the optimization procedure. The safety index approach employed allows us to use semi-analytical formulas to calculate the sensitivity derivatives of the safety constraints.

The new approach is applied to the design of a simple structure. Both methods are robust to a satisfactory degree. The results are compared to those obtained by the safety index approach without integrating the analysis and design processes. The new methods substantially reduce the computational cost of optimization, which indicates that integrated analysis and design has the potential of removing a major obstacle, which is the excessive computational cost, in applying stochastic optimization to real life structural design. 


\section{Acknowledgements}

I am indebted to Dr. Efstratios Nikolaidis for the help and guidance he has given me throughout this work. I wish to thank Dr. R.T. Haftka and Dr. O.F. Hughes for serving on my committee and for their fruitful comments.

I take this opportunity to thank all my friends and especially , for the physical and psycological help and the encouragement they gave me.

This thesis is dedicated to my parents and and to my sister 


\section{Table of Contents}

Introduction $\ldots \ldots \ldots \ldots \ldots \ldots \ldots \ldots \ldots \ldots \ldots \ldots \ldots \ldots \ldots \ldots \ldots \ldots \ldots$

Iterative Solution Using the Safety Index Approach $\ldots \ldots \ldots \ldots \ldots \ldots \ldots$

2.1 Formulation of the Problem $\ldots \ldots \ldots \ldots \ldots \ldots \ldots \ldots \ldots \ldots$

2.2 The Chance Constraint Programming Technique. $\ldots \ldots \ldots \ldots \ldots \ldots \ldots \ldots$

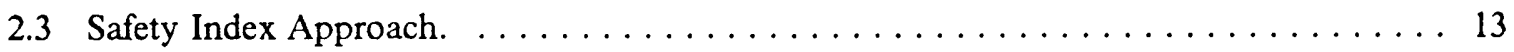

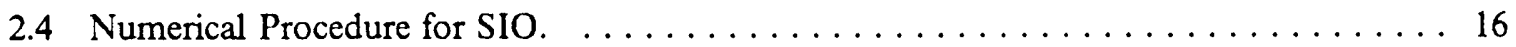

Semi-analytical Equations for Sensitivity Derivatives $\ldots \ldots \ldots \ldots \ldots \ldots \ldots \ldots$

3.1 Sensitivity Analysis for Safety Index. $\ldots \ldots \ldots \ldots \ldots \ldots \ldots \ldots \ldots \ldots \ldots \ldots \ldots \ldots \ldots$

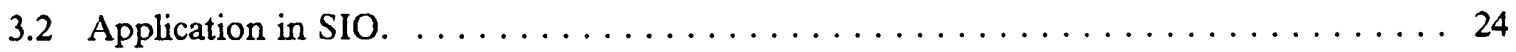

Optimization Procedure for Simultaneous Analysis and Design $\ldots \ldots \ldots \ldots$

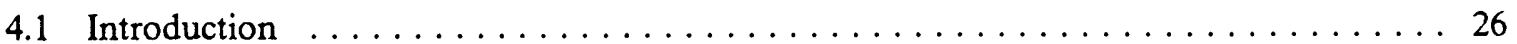

4.2 First Method: One Iteration for Directional Cosines per Failure Surface . . . . . . . 27

4.3 Second Method: Use the Sensitivity Derivatives to Estimate the Safety Index for each Intermediate Design. . . . . . . . . . . . . . . . . . . . . . . . . . 29 
Numerical Example, Results and Discussions

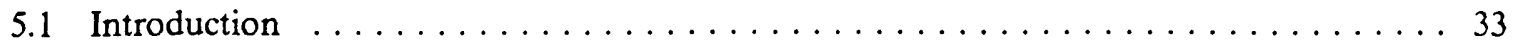

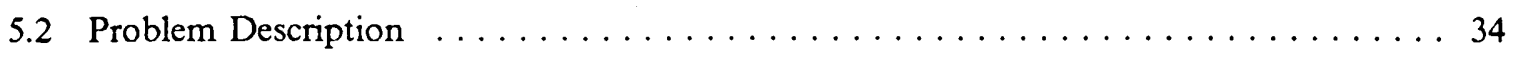

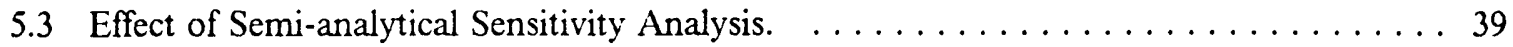

5.4 Validation of the Optimization Procedure $\ldots \ldots \ldots \ldots \ldots \ldots \ldots \ldots \ldots \ldots$

5.5 Optimization Results $\ldots \ldots \ldots \ldots \ldots \ldots \ldots \ldots \ldots \ldots \ldots \ldots \ldots \ldots \ldots \ldots \ldots$

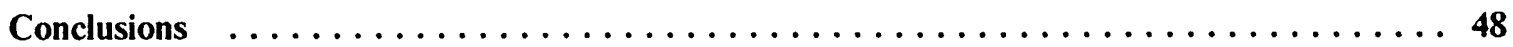

Bibliography $\ldots \ldots \ldots \ldots \ldots \ldots \ldots \ldots \ldots \ldots \ldots \ldots \ldots \ldots \ldots \ldots \ldots \ldots$

Vita $\ldots \ldots \ldots \ldots \ldots \ldots \ldots \ldots \ldots \ldots \ldots \ldots \ldots \ldots \ldots \ldots \ldots \ldots \ldots \ldots \ldots$ 


\section{List of Illustrations}

Figure 1. Flow-chart for Original SIO Method. $\ldots \ldots \ldots \ldots \ldots \ldots$

Figure 2. Iterative procedure for Original SIO method. ......... 54

Figure 3. Iterative procedure for the First ASIO Method. ......... 55

Figure 4. Flow-chart for the First ASIO Method. ............ 56

Figure 5. Iterative procedure for the Second ASIO Method. . . . . . 57

Figure 6. Flow-chart for the Second ASIO Method. ........... 58

Figure 7. Cable stayed cantilevered box-beam. ............. 59

Figure 8. Objective function for each iteration, for Case 3 and $\beta=2.33$. . 60

Figure 9. Safety index for each iteration, for Case 3 and $\beta=2.33$. Method 1. ..........................61

Figure 10. Safety index for each iteration, for Case 3 and $\beta=2.33$. Method

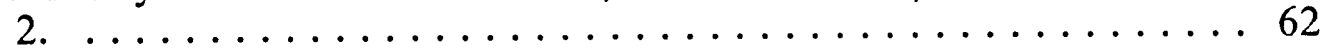

Figure 11. Safety index for each iteration, for Case 3 and $\beta=2.33$. Method

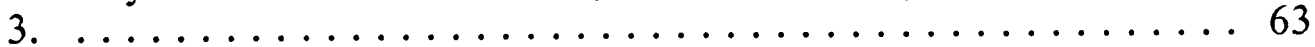

Figure 12. CPU time for the three methods, for Case 5 and $\beta=1.28 . \ldots 64$ 


\section{List of Tables}

Table 1. Random parameters and their statistics. .......... 65

Table 2. Comparison of Computational Time between original SIO (1) and SIO with sensitivity analysis (2) Methods. Case $1 . \ldots \ldots \ldots 66$

Table 3. Comparison of Computational Time between original SIO (1) and SIO with sensitivity analysis (2) Methods. Case $2 . \ldots \ldots \ldots 67$

Table 4. Comparison of Computational Time between original SIO (1) and SIO with sensitivity analysis (2) Methods. Case $3 . \ldots \ldots \ldots 68$

Table 5. Comparison of Computational Time between original SIO (1) and SIO with sensitivity analysis (2) Methods. Case 4. . . . . . . . 69

Table 6. Comparison of Computational Time between original SIO (1) and SIO with sensitivity analysis (2) Methods. Case 5. . . . . . . . 70

Table 7. Comparison of Objective Function between SIO with sensitivity analysis (1) and ASIO (2 and 3) Methods. Case 1......... 71

Table 8. Comparison of Objective Function between SIO with sensitivity analysis (1) and ASIO (2 and 3 ) Methods. Case 2. ........ 72

Table 9. Comparison of Objective Function between SIO with sensitivity analysis (1) and ASIO (2 and 3) Methods. Case 3. ........ 73

Table 10. Comparison of Objective Function between SIO with sensitivity analysis (1) and ASIO (2 and 3 ) Methods. Case 4. ........ 74

Table 11. Comparison of Objective Function between SIO with sensitivity analysis (1) and ASIO (2 and 3) Methods. Case 5. ........ 75

Table 12. Final design for SIO method for $\beta=2.33$ and initial design vector

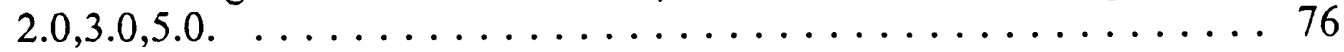


Table 13. Final design for the First ASIO method for $\beta=2.33$ and initial design vector $1.0,1.5,2.5 . \ldots \ldots \ldots \ldots \ldots \ldots \ldots \ldots$

Table 14. Final design for the First ASIO method for $\beta=2.33$ and initial design vector $4.0,6,0,10.0 \ldots \ldots \ldots \ldots \ldots \ldots \ldots \ldots$

Table 15. Final design for the Second ASIO method for $\beta=2.33$ and initial design vector $1.0,1.5,2.5 . \ldots \ldots \ldots \ldots \ldots \ldots \ldots . \ldots \ldots$

Table 16. Final design for the Second ASIO method for $\beta=2.33$ and initial design vector $4.0,6.0,10.0 . \ldots \ldots \ldots \ldots \ldots \ldots \ldots$

Table 17. Comparison of Computational Time between SIO with sensitivity analysis (1) and ASIO (2 and 3) Methods. Case 1.........81

Table 18. Comparison of Computational Time between SIO with sensitivity analysis (1) and ASIO (2 and 3 ) Methods. Case 2. . . . . . . 82

Table 19. Comparison of Computational Time between SIO with sensitivity analysis (1) and ASIO (2 and 3 ) Methods. Case $3 . \ldots \ldots \ldots \ldots$

Table 20. Comparison of Computational Time between SIO with sensitivity analysis (1) and ASIO (2 and 3) Methods. Case 4. . ....... 84

Table 21. Comparison of Computational Time between SIO with sensitivity analysis (1) and ASIO (2 and 3 ) Methods. Case 5. ........ 85

Table 22. Computational time breakdown for $\beta=2.33$ for SIO (1), SIO with sensitivity analysis ( 2 ) and ASIO (3 and 4 ) methods. ...... 86

Table 23. Number of analyses required for $\beta=2.33$ for SIO (1), SIO with sensitivity analysis ( 2 ) and ASIO ( 3 and 4$)$ methods. . . . . . 87

Table 24. Comparison of Objective Function between original SIO (Method 1) and ASIO (Methods 2 and 3). Case 1.

Table 25. Comparison of Objective Function between original SIO (Method 1) and ASIO (Methods 2 and 3). Case 2.

Table 26. Comparison of Objective Function between original SIO (Method 1) and ASIO (Methods 2 and 3). Case 3.

Table 27. Comparison of Objective Function between original SIO (Method 1) and ASIO (Methods 2 and 3). Case 4. 
Table 28. Comparison of Objective Function between original SIO (Method 1) and ASIO (Methods 2 and 3). Case 5. ........... 92

Table 29. Comparison of Computational Time between SIO with sensitivity analysis (Method 1) and ASIO (Methods 2 and 3). Case 1. ....93

Table 30. Comparison of Computational Time between SIO with sensitivity analysis (Method 1) and ASIO (Methods 2 and 3). Case 2. .... 94

Table 31. Comparison of Computational Time between SIO with sensitivity analysis (Method 1) and ASIO (Methods 2 and 3). Case 3. .... 95

Table 32. Comparison of Computational Time between SIO with sensitivity analysis (Method 1) and ASIO (Methods 2 and 3). Case 4. ....996

Table 33. Comparison of Computational Time between SIO with sensitivity analysis (Method 1) and ASIO (Methods 2 and 3). Case 5. . ... 97 


\section{Chapter 1}

\section{Introduction}

Structural optimization has seen remarkable progress in recent years and is now recognized as a practical design tool. The development of the above method was associated with the advancement in several other areas like:

- Establishment of finite element methods.

- Advancement in computer technology.

- Creation of new, more efficient and robust optimization algorithms.

- Development of semi-analytical procedures for sensitivity analysis. By semi-analytical we mean that the expressions developed, involved terms, that had to be calculated numerically. 
However, it is generally recognized that structural problems are often non-deterministic and, consequently, decisions have to be made in the presence of uncertainties. That gave birth, in the last one-two decades to systematic procedures for decision making under uncertainties, through the concept of reliability.

In general, a stochastic programming problem is an optimization problem in which some or all of the parameters are described by random variables rather than by deterministic quantities. The basic idea of all stochastic programming methods is to convert the probabilistic problem into an equivalent deterministic one.

One of the first publications dealing with reliability based optimization design was published by F. Moses and D.E. Kinser [1]. There, techniques for finding the minimum weight design of a multi-load, multi-element structure with a prescribed level of safety have been described. Any form of frequency distribution for loads and strengths can be treated, but the probabilistic analysis is applicable only to conventional structures, for which there is a valid structural analysis. It was also demonstrated that an overall level of structural safety can be prescribed in terms of a rational criterion, like the probability of failure, and minimum weight structures can be designed to meet the prescribed safety level.

Thoft-Christensen and Sorensen [2,3], established a procedure for system reliability based optimization for framed structures, using the beta-unzippinng method for estimating system reliability. Sensitivity derivatives of the safety index of each failure element of the system were calculated using semi-analytical 
formulas. Feng and Moses [4], derived an optimality criterion for sizing the components of framed structures, that satisfy a system reliability constraint. This criterion, which is a special case of the Kuhn-Tucker conditions, states that at the optimum, the sensitivity derivatives of the system reliability with respect to the weight of the structural members are all equal. An algorithm for structural optimization, based on the above criterion, was described in the same reference. The effect of the requirement for high structural redundancy to the final design, when using system reliability optimization, was studied by the same authors [5]. It was concluded that for structures with low degree of indeterminacy, the requirement for high redundancy and low weight or cost oppose each other.

Two main approaches in evaluating reliability have been developed [22]. In the first, expansion around the mean values of the random variables is taken to evaluate constraint sensitivities. This is called Mean Value First Order Second Moment (MVFOSM) method. In the second approach the linearization point lies on the failure surface and it corresponds to the maximum likelihood of failure occurence. This method is called Advanced First Order Second Moment (AFOSM).

An application of the (MVFOSM) method was presented by Rao in [6]. Results corresponding to both deterministic and stochastic formulations of the problem were presented. The optimization method using the MVFOSM approach to evaluate $\beta_{i}$ is called Chance Constraint Programming (CCP) technique. It was shown that the objective function increases, if the specified 
constraints have to be satisfied with a higher probability. Examples of application of the CCP technique can also be found in [18-20].

An alternative approach to the above optimization technique, using an Advanced First Order Second Moment Method, was presented by Nikolaidis and Burdisso in [7]. It was called Safety Index Optimization (SIO), because the constraints were expressed in terms of the safety index that corresponded to the physical constraints. The basic drawbacks of classical Chance Constraint Optimization, like the lack of invariance and the inaccuracy of the results, when the constraints are highly non-linear, were shown to be overcome.

Frangopol gave an interactive reliability-based CAD optimization procedure for plastic design of framed structures, which accounts for the correlation between various loads and strengths [8]. Since the procedure is interactive it can give an insight to the reliability optimization problem. A technique for sensitivity analysis of the optimum design was presented by the same author [9]. It was shown that the optimum solution can be more sensitive to the correlation between the strengths of the structural members than to the method employed to evaluate the failure probability.

Rao used element reliability optimization to design an aircraft wing subjected to gust and landing loads [10]. The constraints for the safety of the wing were evaluated by the first order, second moment method. However, no comparison was made between the results of the deterministic and the probabilistic approaches. 
The lack of information about the variability of the system parameters and the high computational cost are only some of the main difficulties in dealing with stochastic optimization. Another significant problem associated with this type of optimization problems is to estimate the gradients of the reliability constraints. In general, numerical determination of the sensitivity coefficients of the reliability constraints is not practical, because it requires a large number of reliability index calculations and, most probably, finite element analyses of the structural system. Therefore, a great deal of effort has been directed towards the sensitivity analysis of the reliability constraints by using semi-analytically determined derivatives.

A method for sensitivity analysis of stochastic optimization problems was presented in [11]. A general strategy for sensitivity analysis for single mode failure probability was developed. This strategy was applied to the specific case of problems including constraints on eigenvalues. An AFOSM method was used to evaluate reliability. The results were applicable for general cases, where the failure state can only be defined implicitly through a set of state equations. Also, since the resulting sensitivity coefficient contains only first order derivatives, with respect to design variables, the method is very suitable for numerical implementation.

Sensitivity analysis using semi-analytical derivatives was performed by Sorensen in [12]. Solution of the element reliability-based optimization proved to be efficient, because the sensitivity derivatives could be determined using closed form equations. Both formulations with element and system reliability 
constraints were discussed. Formulas for the sensitivity derivatives, for the case of independent Gaussian variables were also presented by Pinsker in [13].

Real life optimization almost always includes non-linear problems, which involve many variables and usually probabilistic constraints. The above facts lead to a high computational cost, when dealing with real life problems, and, therefore, the need to find ways to reduce computational effort emerges as a necessity.

One alternative is to integrate the analysis and optimization procedures, thus improving the efficiency of the whole method. The approach of Haftka and Kamat [14], was attractive for poorly banded three dimensional problems, where the use of Gaussian elimination to solve the iterative non-linear analysis is not practical.

The use of a milder form of integration of analysis and design was explored by Haftka [15]. The optimization process began with a linearized structural response and the amount of non-linearity was increased as one got closer to the optimum design. This integrated analysis and design method is a sequential approximate optimization approach and its objective is to reduce the cost of the non-linear analyses required for the optimization to the cost of a single analysis. The method was based on performing the load increment iteration in parallel with the optimization iteration.

Another related publication [16], dealt with the optimum design of a hole in a plate in tension, which is obtained with a design algorithm, that integrates the 
convergence of the analysis and design iterations. It was shown that significant reduction of the number of analysis iterations can be achieved.

The purpose of the present work is to demonstrate the viability of integrated analysis and design and its potential in reducing the computational effort in stochastic optimization. This is done by applying some techniques based on the idea of integrated analysis and design to a simple problem originally studied in [7]. We will try to improve the efficiency of the above method by:

1. Implementing a semi-analytical method for the evaluation of the sensitivities of the constraints. The method is an application of the sensitivity formulas presented in [23].

2. Integrating the analysis and design procedures. For the above to be achieved the intermediate steps of the optimization procedure will be completed only to partial convergence. Two methods will be examined.

Since reliability based optimization is in general an iterative procedure, any attempt to decrease the amount of calculations performed in each iterative step is possible to result in big savings in computational time, the savings increasing in absolute numbers, as the problem becomes more complicated.

The basic features of the AFOSM method (linearization about the most probable failure point) will be retained. The whole analysis is based on the assumption of independent Gaussian variables, but with some modifications and approximations it can be applied to any kind of random variables. The same 
example, as in [7], will be examined, in order to demonstrate the higher efficiency of the new method.

In Chapter 2 an overview of the general techniques used in reliability optimization is presented. Chapter 3 describes the semi-analytical model for sensitivity derivative evaluation. Chapter 4 presents the optimization procedures for integrated analysis and design. In Chapter 5 the results obtained from applying the new approaches to a simple design problem are compared to those obtained by classical Safety Index Optimization [7]. 


\section{Chapter 2}

\section{Iterative Solution Using the Safety Index Approach}

\subsection{Formulation of the Problem}

In this chapter an overview of the general techniques used in reliability optimization is presented. A reference to some methods for evaluating the safety index is also made.

In general, a stochastic optimization problem can be defined as follows. Find the vector of the design variables $\mathbf{X}$ minimizing some objective function, such as the cost or weight of the system, subjected to constraints usually associated with reliability of the structure. That is:

minimize $\quad F(\mathbf{X}, \mathbf{Y})$ 
subject to

$$
P\left[g_{i}(\mathbf{X}, \mathbf{Y}) \geq 0\right] \geq p_{i}, \quad i=1, \ldots, m
$$

where $\mathbf{Y}$ is the vector of $n$ random variables involved in the optimization problem; $P$ [.] denotes the probability of the event [.], and $p_{i}$ is the required probability of survival for the $i$ th constraint or failure mode $g_{i}(\mathbf{Y})$. In the case where some or all the design variables are also random we optimize the mean value of these variables. In the following we drop $\mathbf{X}$ for simplicity.

The objective function, $F(\mathbf{Y})$, is a function of several random variables, and thus it is also a random variable. Its mean and standard deviation can be approximated by expanding $F(\mathbf{Y})$ in Taylor series around the mean values of the random variables and retaining up to linear terms. That is:

$$
F(\mathbf{Y})=F(\overline{\mathbf{Y}})+\sum_{i=1}^{n} \frac{\partial F}{\partial Y_{i}}\left(Y_{i}-\bar{Y}_{i}\right)+\left.\frac{1}{2} \sum_{i=1}^{n} \sum_{j=1}^{n} \frac{\partial^{2} F}{\partial Y_{i} \partial Y_{j}}\right|_{y_{i}}\left(Y_{i}-\bar{Y}_{i}\right)\left(Y_{j}-\bar{Y}_{j}\right)
$$

where $Y_{i}$ is the ith random variable, $y_{i}$ 's are between $Y_{i}$ and $\bar{Y}_{i}$, and the bar (-) stands for the mean value. By taking the mean of $F(\mathbf{Y})$ we have:

$\bar{F}(\mathbf{Y})=F(\overline{\mathbf{Y}})+\left.\frac{1}{2} \sum_{i=1}^{n} \sum_{j=1}^{n} \frac{\partial^{2} F}{\partial Y_{i} \partial Y_{j}}\right|_{y_{i}} \operatorname{Cov}\left(Y_{i}, Y_{j}\right)$

where $\operatorname{Cov}\left(Y_{i}, Y_{j}\right)$ is the covariance between the random variables $Y_{i}$ and $Y_{j}$. As we can observe for small values of the covariances $\operatorname{Cov}\left(Y_{i}, Y_{j}\right), \bar{F}(\mathbf{Y})$ can be approximated by $F(\overline{\mathbf{Y}})$. 
The standard deviation is given by the expression:

$$
\begin{aligned}
& \sigma^{2}(F)=\sum_{i=1}^{n} \sum_{j=1}^{n} \frac{\partial F}{\partial Y_{i}} \frac{\partial F}{\partial Y_{j}} \operatorname{Cov}\left(Y_{i}, Y_{j}\right)+ \\
& \left.\left.\sum_{i=1}^{n} \sum_{j=1}^{n} \sum_{k=1}^{n} \frac{\partial^{2} F}{\partial Y_{i} \partial Y_{j}}\right|_{y_{i}} \frac{\partial F}{\partial Y_{k}}\right|_{y_{k}}\left(Y_{i}-\bar{Y}_{i}\right)\left(Y_{j}-\bar{Y}_{j}\right)\left(Y_{k}-\bar{Y}_{k}\right)+\text { H.O.T. }
\end{aligned}
$$

For small coefficients of variation the second term on the right hand side of the above expression is small compared to the first one and can be neglected.

\subsection{The Chance Constraint Programming Technique.}

The constraint function $g_{i}(\mathbf{Y})$ represents each mode of malfunction of the system. For given values of the random variables this function separates the space of random variables into two:(a) the safe space in which the constraint is satisfied $\left(g_{i}(\mathbf{Y})>0\right)$; and (b) the failure space in which the constraint is violated $\left(g_{i}(\mathbf{Y})<0\right)$. The boundary between these two regions $g_{i}(\mathbf{Y})=0$ is called failure surface. The function $g_{i}(\mathbf{Y})$ is also called limit state function.

In practice, the information about the uncertainties is generally limited to the first few moments; namely the expected values (first moments) and covariances (second moments) of the random variables. Thus, practical evaluation of 
reliability has been developed in terms of these two moments. One such approximation has been proposed by Cornell [17]. According to this method the probability of safety, $P_{s i}$, can be approximated as in the following formula:

$P_{s i} \simeq \Phi\left(\beta_{i}\right)$

where $\Phi($.$) is the standard normal probability distribution function, and \beta_{i}$ is the reliability or safety index for the $i$ th failure mode defined as follows:

$\beta_{i}=\frac{\bar{g}_{i}(\mathbf{Y})}{\sigma\left(g_{i}\right)}$

The constraint function $g_{i}(\mathbf{Y})$ is in general a non-linear function of the random variables. Thus, the mean and variance, required in eq. (2.2.2) cannot be computed in exact form by the first and second moments of the random parameters alone. To overcome this difficulty the constraint function is linearized by means of a Taylor series expansion around an appropriate point $\mathbf{Y}^{*}$. Retaining up to first order terms $g_{i}(\mathbf{Y})$ can be written as follows:

$g_{i}=g_{i}\left(\mathbf{Y}^{*}\right)+\sum_{r=1}^{n} \frac{\partial g_{i}}{\partial Y_{r}}\left(Y_{r}-Y_{r}^{*}\right)$

Substituting eqn. (2.2.3) into (2.2.2) gives: 


$$
\beta_{i}=\frac{g_{i}\left(\mathbf{Y}^{*}\right)+\sum_{r=1}^{n} \frac{\partial g_{i}}{\partial Y_{r}}\left(\bar{Y}_{r}-Y_{r}^{*}\right)}{\left(\sum_{r=1}^{n} \sum_{s=1}^{n} \frac{\partial g_{i}}{\partial Y_{r}} \frac{\partial g_{i}}{\partial Y_{s}} \operatorname{Cov}\left(Y_{r}, Y_{s}\right)\right)^{1 / 2}}
$$

The reliability index depends both on the specific form of the failure function and on the choice of the linearization point $\mathbf{Y}^{*}$. In structural optimization the point corresponding to the mean value of the random variables has been customarily considered as the linearization point. The method for evaluating $\beta_{i}$ by expanding around the mean value is known as the mean value first-order second moment (MVFOSM) method.

However, two problems have been commonly associated with the above method. First, the results are inaccurate when $g_{i}(\mathbf{Y})$ is highly non-linear, and the coefficients of variation of the random variables are high. The second problem is the lack of invariance of the safety index. This means that the CCP technique yields different optimal points when the constraints are expressed in different equivalent forms.

\subsection{Safety Index Approach.}

Hasofer and Lind [21] proposed a method for evaluating the safety index that overcomes the drawbacks of the MVFOSM method. According to their 
approach the constraint function is again linearized using a Taylor expansion retaining up to first order terms. The safety index is evaluated using eq.(2.2.4). The difference from the MVFOSM method is that the linearization point lies on the failure surface. The point selected is that of maximum likelihood of failure occurence and is known as the most probable failure point. This method is called advanced first-order, second-moment (AFOSM) method.

To determine the location of the most probable failure point, the set of original random variables $\mathbf{Y}$ is mapped into a normalized and uncorrelated set of reduced variables $\mathbf{Z}$. Thus, the transformation can be written as follows:

$$
\mathbf{Z}=\mathbf{A}(\mathbf{Y}-\overline{\mathbf{Y}})
$$

where $\mathbf{A}$ is the orthogonal transformation matrix and $\overline{\mathbf{Y}}$ is the point corresponding to the mean values of the random variables. This matrix can be obtained from the eigenvalue analysis of the covariance matrix of the original random variables $\mathbf{C}_{\boldsymbol{y}}$. An alternative transformation is to define matrix $\mathbf{A}$ as a lower-triangular matrix through the Rosenblatt transformation. In any case, A must satisfy the following equation:

$$
\mathbf{C}_{z}=\mathbf{A}^{T} \mathbf{C}_{y} \mathbf{A}=I
$$

By the same transformation of eqn (2.3.1) the failure surface is mapped onto the corresponding failure surface in the reduced space. It can be shown [22] that the point on this surface with minimum distance from the origin is the mapping 
of the most probable failure point. Furthermore, its geometric distance to the origin is equal to the safety index $\beta_{i}$.

Since the failure surface is, in general a non-linear function of the random parameters, the expansion point is not known a priori. Thus, the point with minimum distance to the origin can be found by solving the following optimization problem:

minimize

$$
\left(\mathbf{Z}^{T} \mathbf{Z}\right)^{1 / 2}=\beta_{i}
$$

subject to

$$
g_{i}(\mathbf{Z})=0
$$

where $g_{i}(\mathbf{Z})$ is the failure function in the reduced space. Several algorithms to solve for the expansion point and the associated safety index are available in the literature [22-24]. The optimization approach using the AFOSM method in evaluating the constraints is an alternative for reliability based optimization. This approach will be referred as safety index optimization (SIO).

After evaluating the safety indices, using either the MVFOSM method or the AFOSM method the constraints in eqn (2.1.1) can be expressed in terms of the safety indices $\beta_{i}$, as follows [7]:

$$
G_{i}(\mathbf{Y})=\beta_{i}-r\left(p_{i}\right) \quad i=1, \ldots, m,
$$

where

$$
r\left(p_{i}\right)=\Phi^{-1}\left(p_{i}\right)
$$


and $\Phi^{-1}($.$) denotes the inverse probability distribution function of a canonical$ Gaussian random variable. Equations (2.3.4) expressing the $m$ constraints are used in the optimization algorithm.

\subsection{Numerical Procedure for SIO.}

Solving a structural problem by using a safety index approach is, usually, an iterative procedure, which may involve several nested iteration loops. A general, simple algorithm for evaluating reliability for a certain design has been suggested by Rackwitz (1976) [22]. According to this algorithm, after finding the reduced variables we calculate the direction cosines $\alpha_{i}=\frac{\partial g / \partial z_{i}}{\left(\sum_{i=1}^{n}\left(\partial g / \partial z_{i}\right)^{2}\right)^{1 / 2}}$. Then we find $\beta$

and we repeat to convergence. The algorithm goes as follows:

1. Assume initial values of the random variables $y_{i}^{*} ; \quad i=1,2, \ldots, n$ and obtain the reduced variables: $z_{i}^{*}=\frac{y_{i}^{*}-\mu_{Y_{i}}}{\sigma_{Y_{i}}}$

2. Evaluate $\left(\frac{\partial g}{\partial z_{i}}\right)$. and $\alpha_{i}^{*}$ (direction cosines) at $y_{i}$.

3. Form $y_{i}^{*}=\mu_{Y_{i}}-\alpha_{i}^{*} \sigma_{Y_{i}} \beta$.

4. Substitute above $y_{i}^{*}$ in $g\left(y_{1}^{*}, y_{2}^{*}, \ldots, y_{n}^{*}\right)=0$ and solve for $\beta$. In general, this is a non-linear equation and solution can be obtained only numerically. 
5. Using the $\beta$ obtained in step 4 , reevaluate $z_{i}^{*}=-\alpha_{i} \beta$.

6. Repeat steps 2 through 5 until convergence is obtained.

Other techniques for evaluating the safety index have been investigated and compared by Liu and Kiureghian [24].

An application of the SIO method using the Rackwitz algorithm was presented in [7]. It consisted mainly of three nested loops for each constraint:

Outer loop. The optimization algorithm systematically modifies the values of the design variables, so that the objective function decreases or the degree of constraint satisfaction is improved. For each new point on the failure surface, in the reduced variables space, the objective function, the constraints and the sensitivity derivatives are calculated. This iterative procedure is repeated until convergence is obtained.

Intermediate loop. It concerns the evaluation of the direction cosines that correspond to the minimum distance from the origin of the reduced variables space to the failure surface. Initially, for each failure surface direction cosines same as those around the mean value are assumed. Thus new values of the reduced variables $z_{i}^{*}=-\alpha_{i} \beta$ are obtained. From those values of $\mathbf{Z}$ new direction cosines are obtained and the procedure is repeated to convergence. 
Inner loop. This consists of step 4 of the Rackwitz algorithm as it is described above. Here, for a given failure surface and direction cosines the distance from the origin to the failure surface in the given direction is found by an iterative linear interpolation method.

A flow-chart of the above method is presented in Fig. 1. The procedure constituting the intermediate and the inner loops is depicted in Fig. 2 for the simple case of two random variables. In this figure point 0 represents the mean. According to the values of the design variables, at a point, a limit state function $g=0$ is determined. Then, direction cosines same as those about the mean values of the random variables are assumed (direction $0 M$ ). In order to find the distance from 0 to $M$, we solve the equation $g\left(\mathbf{Y}^{*}\right)=0$, usually numerically, as we have already mentioned. The length $0 M$ is the solution of the following set of equations:

$z_{1}=-\alpha_{1} \times 0 M$

$z_{2}=-\alpha_{2} \times 0 M$

$g\left(z_{1}, z_{2}\right)=0$

This procedure corresponds to the inner loop mentioned above.

When we have more than two variables, the procedure is similar, but instead of having a 2-dimensional space we have an $n$-dimensional space, where $n$ is the number of random variables. 
After point $M$ has been found, new, improved values for the direction cosines are evaluated for the same failure surface (direction $0 M^{\prime}$ ). Then the procedure described above is used to find the length $0 M^{\prime}$. This way the most probable failure point $A$ for the given surface is obtained. The procedure of improving the direction cosines corresponds to the intermediate loop mentioned above. The distance $0 \mathrm{~A}$ can then been considered as an approximation for the safety index $\beta$.

In [7] each iteration loop is solved to full convergence at every step. This, combined with the fact that wherever derivatives are needed, they are calculated by a finite-difference method leads to the conclusion that application of the above method can be very expensive computationally, especially when the problem involves many design variables. 


\section{Chapter 3}

\section{Semi-analytical Equations for Sensitivity Derivatives}

\subsection{Sensitivity Analysis for Safety Index.}

Here, the semi-analytical equations for the sensitivity analysis are presented. The formulas given in [23] are used.

Almost in every optimization problem the sensitivity of the safety index $\beta$ with respect to various input parameters needs to be determined. The sensitivity factors are very useful in determining the change in reliability for a specific change in an input parameter without performing a reanalysis.

In contrast to the sensitivity coefficients of the objective function, which are usually easily obtained by numerical differentiation (finite differences), numerical determination of the sensitivity coefficients of the reliability constraints is generally not efficient to use in practice, because it requires a large number of 
reliability calculations and finite element analyses of the structural system. That is why the use of approximate semi-analytical methods for sensitivity calculations emerges as a necessity in these cases.

The sensitivity of the safety index $\beta$ with respect to the mean value of a Gaussian random variable can be written as:

$$
\frac{\partial \beta}{\partial \mu_{i}}=\frac{\partial \beta}{\partial z_{i}} \frac{\partial z_{i}}{\partial \mu_{i}}
$$

where $z_{i}$ is a reduced normalized (i.e. zero mean and unit variance) Gaussian variate defined as:

$$
z_{i}=\frac{y_{i}-\mu_{i}}{\sigma_{i}}
$$

where $\mu_{i}$ and $\sigma_{i}$ are the mean and the standard deviation, respectively, of the random variable $y_{i}$.

For a deterministic design parameter $p$, it is [23]:

$$
\frac{\partial \beta}{\partial p}=\frac{\partial g / \partial p}{\left|\nabla g_{z}\left(\mathbf{Z}^{*}\right)\right|}
$$

In general, $\partial g / \partial p$ can be calculated numerically, as it is also mentioned in [12]. Thus, the above expression is semi-analytical, since one of the terms has to be calculated numerically.

In the case where $p$ is a statistical distribution parameter and since in this case $g(\mathbf{Y})=g\left(\mathbf{A}^{-1}(\mathbf{Z})\right)$, we can write: 
$\frac{\partial g}{\partial p}=\left(\frac{\partial g}{\partial z_{1}}, \frac{\partial g}{\partial z_{2}}, \ldots, \frac{\partial g}{\partial z_{n}}\right)\left(\frac{\partial z_{1}}{\partial p}, \frac{\partial z_{2}}{\partial p}, \ldots, \frac{\partial z_{n}}{\partial p}\right)^{T}$

From (3.1.3a) we get:

$\frac{\partial \beta}{\partial p}=\frac{\left(\frac{\partial g}{\partial z_{1}}, \frac{\partial g}{\partial z_{2}}, \ldots, \frac{\partial g}{\partial z_{n}}\right)}{\left|\nabla g_{z}\left(\mathbf{Z}^{*}\right)\right|}\left(\frac{\partial z_{1}}{\partial p}, \frac{\partial z_{2}}{\partial p}, \ldots, \frac{\partial z_{n}}{\partial p}\right)^{T}$

But:

$\frac{\left(\frac{\partial g}{\partial z_{1}}, \frac{\partial g}{\partial z_{2}}, \ldots, \frac{\partial g}{\partial z_{n}}\right)}{\left|\nabla g_{z}\left(\mathbf{Z}^{*}\right)\right|}=\alpha=\frac{\mathbf{Z}^{*} T}{\beta}$

and

$\left(\frac{\partial z_{1}}{\partial p}, \frac{\partial z_{2}}{\partial p}, \ldots, \frac{\partial z_{n}}{\partial p}\right)^{T}=\frac{\partial \mathbf{A}}{\partial p}$

As a result for a general statistical distribution parameter $p$ the sensitivity derivative, $\frac{\partial \beta}{\partial p}$, is :

$\frac{\partial \beta}{\partial p}=\frac{1}{\beta} \mathbf{Z}^{* T} \frac{\partial \mathbf{A}}{\partial p}$

where $\mathbf{Z}^{*}$ is the design point and $\mathbf{A}$ is a transformation from the original random variables into a set of mutually independent and normalized Gaussian variables. Thus, for independent variables: 


$$
\mathbf{A}=\Phi^{-1}\left(F_{X_{i}}\left(X_{i}\right)\right)
$$

As one can easily observe, in the case of normal variables, $\mathbf{A}$ is identical to the vector of the reduced variables $\mathbf{Z}$. As a result:

$\frac{\partial \beta}{\partial z_{i}}=\frac{1}{\beta}\left(z_{1}^{*}, z_{2}^{*}, \ldots, z_{n}^{*}\right)\left(\frac{\partial z_{1}}{\partial z_{i}}, \frac{\partial z_{2}}{\partial z_{i}}, \ldots, \frac{\partial z_{n}}{\partial z_{i}}\right)^{T}$

Since the assumption of independent variables has already been made, the only non-zero component of the vector of the partial derivatives is $\frac{\partial z_{i}}{\partial z_{i}}$ which, obviously, equals one. Consequently:

$\frac{\partial \beta}{\partial z_{i}}=\frac{1}{\beta} z_{i}^{*}$

Eq. (3.1.2) yields:

$\frac{\partial z_{i}}{\partial \mu_{i}}=-\frac{1}{\sigma_{i}}$

Therefore, eq. (3.1.1) becomes:

$\frac{\partial \beta}{\partial \mu_{i}}=-\frac{z_{i}^{*}}{\beta \sigma_{i}}$

Similarly, it can be proven that:

$$
\frac{\partial \beta}{\partial \sigma_{i}}=-\frac{\left(z_{i}^{*}\right)^{2}}{\beta \sigma_{i}}
$$


Summarizing, the sensitivity formulas for the safety index in general require numerical evaluation of the derivatives $\frac{\partial g}{\partial p}$, before they can be applied. In the special case of Gaussian and mutually independent variables, the formulas reduce to the simple analytical forms of eqs. (3.1.8) and (3.1.9), which do not require any numerical evaluations.

\subsection{Application in SIO.}

The optimization algorithm used in the present work requires the derivatives of the constraints with respect to the design variables, i.e.:

$\frac{\partial g}{\partial x_{i}}, \quad i=1,2, \ldots, n_{d v}$

where $n_{d v}$ is the number of the design variables used in the problem. In our case the reliability constraints are expressed as:

$g_{j}(\mathbf{X})=\beta_{j}(\mathbf{X})-c, \quad j=1,2, \ldots, n_{c}$

where $n_{c}$ is the number of constraints, $\mathbf{X}$ is the vector of design variables and $c$ is a constant corresponding to the desired probability of safety. Consequently:

$$
\frac{\partial g_{j}}{\partial x_{i}}=\frac{\partial \beta_{j}}{\partial x_{i}}
$$


The above derivative, obviously, can also be expressed as:

$$
\frac{\partial \beta_{j}}{\partial x_{i}}=\frac{\partial \beta_{j}}{\partial \mu_{i}} \frac{\partial \mu_{i}}{\partial x_{i}}+\frac{\partial \beta_{j}}{\partial \sigma_{i}} \frac{\partial \sigma_{i}}{\partial x_{i}}
$$

Now, if the assumption for Gaussian and mutually independent variables holds again, which is the case throughout the present work, eqs. (3.1.8) and (3.1.9) can be used to evaluate $\frac{\partial \beta_{j}}{\partial \mu_{i}}$ and $\frac{\partial \beta_{j}}{\partial \sigma_{i}}$ respectively.

In order to find $\frac{\partial \mu_{i}}{\partial x_{i}}$ and $\frac{\partial \sigma_{i}}{\partial x_{i}}$, an expression relating the mean value and the standard deviation to the design variable is needed. This relation depends both on the nature of the problem and on the specific design variables and, generally, it is different for different problems. But once this expression is given, the derivatives $\frac{\partial \mu_{i}}{\partial x_{i}}$ and $\frac{\partial \sigma_{i}}{\partial x_{i}}$ can be readily calculated.

Summarizing, once an intermediate design point has been determined and the corresponding value of $\beta$ has also been calculated, the derivatives $\frac{\partial g_{j}}{\partial x_{i}}$ can be evaluated rather easily and computationally inexpensively. This is because no finite difference method or reanalyses of the system are involved. 


\title{
Chapter 4
}

\section{Optimization Procedure for Simultaneous Analysis}

\author{
and Design
}

\subsection{Introduction}

In the foregoing discussion, it was shown that the SIO involves three nested iterations. The outer is for finding the optimum and the inner two for calculating the safety index. This makes the computational effort prohibitively high for real life design problems. In this chapter two alternate approximate methods, which are based on the idea of integrated analysis and design will be presented. In both methods we use approximate values of the safety index, $\beta$, instead of calculating its exact value in each iteration of the outer loop. The approximation amounts to using a value of $\beta$ obtained by the two inner iterations, without running the 
method to full convergence. In the First method only one iteration is performed for estimating the direction cosines, corresponding to the most probable failure point, per failure surface. In the Second method the already calculated values of the sensitivity derivatives are used to estimate the safety index, $\beta$, at each stage of the design. In the following discussion the two methods will be referred to as Approximate Safety Index Optimizaton (ASIO).

We note that most optimizers do not perform exact evaluation of the constraints in every iteration, but they use constraint approximations to update the values of the constraints. Thus, the constraints are evaluated exactly in only a few iterations. The procedures described next are followed, each time that the optimizer performs an exact evaluation of the constraints.

\subsection{First Method: One Iteration for Directional Cosines}

\section{per Failure Surface}

For the initial design variables vector and for each constraint we get a limit state function $g=0$. One complete iteration cycle will be performed to find the safety index $\beta$ for the initial design. Once point $A$ (Fig. 3) has been determined, the values of the reduced variables $z_{1}, z_{2}$ are known, as well as the sensitivity derivatives of the safety index with respect to the design variables: 
$\frac{\partial \beta}{\partial X_{i}} \quad i=1, \ldots, n_{d v}$

The optimization algorithm, by using the above point and the direction derivatives, will yield a new design point, which will be a better solution to the problem. The updated design point corresponds to a new limit state function $g=0$ (line $B B^{\prime}$, Fig. 3). By assuming direction cosines same as for point $A$, and performing a complete inner loop, we can arrive at point $B^{\prime}$. The difference from SIO is that instead of performing a complete intermediate loop to find the actual most probable failure point on surface $B B^{\prime}$, we perform only one iteration to get improved values for the direction cosines and thus to arrive at point $B$, which is an approximation to the true most probable failure point for this surface, which is point $B^{\prime \prime}$. This point corresponds to a value of the safety index, which, also, constitutes an approximation to the exact value. Now the optimizer finds a new design point based on this approximate value of the safety index. Note that the sensitivity derivatives can still be estimated using the semi-analytical formulas presented in Chapter 3. The above procedure is repeated, and a new failure surface $\left(C C^{\prime}\right)$ is obtained. $C$ becomes the new design point in the reduced variables space and $0 C$ the new approximation for the safety index $\beta$. As we approach the final stages of the design, surfaces $A A^{\prime}, B B^{\prime}, C C^{\prime}$ become almost identical to each other, so that iterations for the direction cosines are performed approximately on the same surface. Consequently, if the problem is reasonably well behaved, we should arrive at the correct optimum. A flow-chart for the above method is given in Fig. 4. 
If the procedure does not converge, we may perform more than one iteration for the direction cosines for each failure surface. Furthermore, we can complete the intermediate loop at some stages of the optimization search - usually the early ones, where the convergence is rapid - and then use the proposed method at the last stages, where the design point and the failure surfaces do not change significantly.

Compared to the original SIO approach, this method has eliminated the intermediate loop. It consists of only two loops; one for finding points on a failure surface given the direction and one for updating the values of the design variables (Fig. 4).

\subsection{Second Method: Use the Sensitivity Derivatives to Estimate the Safety Index for each Intermediate Design.}

This method takes advantage of the derivatives $\frac{\partial \beta}{\partial X_{i}}$, which can be easily calculated for each iteration of the optimization procedure. Schematically the method is presented in Fig. 5. After a particular most probable failure point $A$ (Fig. 2) has been determined, for a given surface, we know the sensitivity derivatives $\frac{\partial \beta}{\partial X_{i}}$. Based on the values of these sensitivity derivatives, the optimization algorithm will update the design point. A new failure surface corresponds to the new values of the design variables. 
The value of the safety index for the new failure surface can be obtained in terms of the value of the safety index at the previous step as:

$\beta^{i+1}=\beta^{i}+\delta \beta^{i}$

where the superscripts refer to the iteration steps of the outer loop (search for the optimum). Now $\delta \beta^{i}$ can be approximated by:

$\delta \beta^{i} \simeq \sum_{j=1}^{n_{d v}} \frac{\partial \beta^{i}}{\partial X_{j}} \delta X_{j}$

This approximation holds better for small changes in the design variables. Since the new direction cosines are not known, the ones from the previous iteration step are used instead. The new values of the reduced variables can be evaluated from:

$z_{j}=-\alpha_{j}^{i} \beta^{i+1} \quad j=1, \ldots, n_{d v}$

Then, one iteration can be performed with the above values of $z_{j}$ to find more accurate direction cosines, on surface $B C$ (Fig. 5). Point $\mathrm{C}$, which is an approximation of the actual most probable failure point, $B^{\prime}$, is used to estimate the safety index. Thus the actual value of the safety index, which is the length of segment $0 B^{\prime}$, is approximated by the length of the segment $0 C$. Based on this approximate value of the safety index, the optimizer finds a new design point and the aforementioned procedure is repeated to estimate the new safety index for that point. A flow-chart for this method is presented in Fig. 6. 
By looking at Fig. 5, we observe that $0 A=\beta^{i}$. Starting from the design point corresponding to the failure surface $A A^{\prime}$ the optimizer should yield a new point corresponding to a new failure surface, $B^{\prime} B^{\prime \prime}$, where $B^{\prime}$ is the most probable failure point for that surface. Since we assumed same direction cosines instead of arriving at point $B^{\prime}$ we arrive at point $B$. Approximately it is:

$A B^{\prime} \simeq A B$

As a result of the above approximation a different failure surface is obtained (line $B C$ ). On this surface one iteration is performed to find improved direction cosines (direction $0 C$ ). Then $0 C$ is assumed to approximate $\beta_{i}$, and the optimizer searches for an updated new design.

It is observed that if point $A$ is reasonably close to the final most probable failure point, then the three surfaces will be very close to each other and convergence to the correct optimum should be reached.

Since this method seems to be more sensitive to the selection of the initial point than the previous one, more than one complete iteration cycles may be needed before the method can be applied. Also, since the approximations lead to a different failure surface from the actual one at each step, there is a chance that points like $B$ and $B^{\prime}$ mentioned before will be relatively far away from each other. This may cause divergence of the method or convergence to a wrong point. Thus, one should expect the second method to be less stable than the first one. But it should be also noted that if the second method converges to the correct 
point, it should do so very fast, in terms of computational time, since the three iteration loops of the original SIO approach have been reduced to just one loop. 


\section{Chapter 5}

\section{Numerical Example, Results and Discussions}

\subsection{Introduction}

The Integrated Analysis and Design approach is applied to the optimization of simple structure consisting of a cable stayed box girder (Fig. 7). The approach utilizes the semi-analytical formulas of Chapter 3 to calculate the sensitivity derivatives of the constraints. Optimization is performed for various levels of reliability of the parameters involved and various required probabilities of survival. Since the example problem has been solved in [7], by utilizing the original SIO approach, the results can be compared to those in [7] and thus the benefits of the new approach can be assessed. 


\subsection{Problem Description}

The random parameters involved in the problem can be classified in three categories; the load, the strength and the geometry parameters.

- Load parameters are the concentrated force applied at the tip and the distributed load.

- Strength parameters are the ultimate stress of the box girder under bending, axial compression and shear, and the ultimate tensile stress of the cable. The box girder is constructed from mild steel, while the cable material is high strength steel.

- Geometry parameters are the web and flange thicknesses and the cable cross-sectional area.

The level of uncertainty in all the above parameters is expressed by their coefficient of variation. For the load parameters, realistic values for the coefficient of variation is in the range of 0.01 to 0.20 [7]. The coefficient of variation of the ultimate strength of mild steel specimens is in the range from 0.01 to 0.10 [7]. The levels of variability in the strength parameters of the box girder are expected to be higher due to the random residual stresses arising during the fabrication process, the geometrical imperfections, flaws in the material and other uncertain factors. As a result, the coefficient of variation of the strength 
parameters is assumed to be in the range from 0.01 to 0.20 [7]. Finally the coefficients of variation in the web and the flange thickness are assumed to be in the range from 0.001 to 0.02 [7].

The present analysis assumes that all the variables are independent and follow the normal distribution. The assumption of independent variables is used to simplify the calculations and it is not a limitation of the proposed approach. The assumption of normal distribution, on the other hand is justified in view of the central limit theorem [6].

Five cases are considered here, which represent five different situations with various levels of uncertainty. The mean values and the coefficients of variation for all these cases are shown in Table 1. The objective function represents the cost of the structure. If the high tensile cable is assumed to have a relative cost five times higher than the material of the beam, the objective function can be written as:

$F(\mathbf{Y})=2\left(B t_{f}+D t_{w}\right) l+5 A_{c}\left(H^{2}+l^{2}\right)^{1 / 2}$

By using the mean values of the above quantities the objective function can be approximated as follows:

$$
\bar{F}(\mathbf{Y}) \simeq F(\overline{\mathbf{Y}})=2\left(B \bar{t}_{f}+D \bar{t}_{w}\right) l+5 \bar{A}_{c}\left(H^{2}+l^{2}\right)^{1 / 2}
$$

The design variables are related to the mean values of the flange thickness $\bar{t}_{f}$ the web thickness $\bar{t}_{w}$, and the cross-sectional area of the cable, $\bar{A}_{c}$. For programming reasons the design variables must be of the same order. 
Consequently, the design variables are normalized according to the following relations:

$\bar{t}_{f}=X_{1}+0.5$

$\bar{t}_{w}=4 X_{2}+2$

$\overline{A_{c}}=10 X_{3}+5$

where $X_{1}, X_{2}, X_{3}$ are the normalized variables. From the above relations it follows easily that:

$\frac{\partial \bar{t}_{f}}{\partial X_{1}}=1$

$\frac{\partial \bar{t}_{w}}{\partial x_{2}}=4$

$\frac{\partial \bar{A}_{c}}{\partial X_{3}}=10$

These are the values used in eq. (3.2.4) for $\frac{\partial \mu_{i}}{\partial X_{i}}$. The constraints are expressed in terms of the safety indices, as described in Section 3.2. The optimization has been performed for required probabilities that the constraints are satisfied equal to $0.5,0.84,0.9,0.95,0.99,0.999$ and 0.9999 .

The first constraint refers to the maximum compressive stress induced to the flange, and the limit state function for this constraint is given by: 
$g_{1}(\mathbf{Y})=1-\left|\frac{f_{a}}{S_{c}}\right|-\left|\frac{f_{b}}{S_{b c}}\right|$

where $f_{a}$ and $f_{b}$ denote the induced, axial and bending, compressive stresses in the flange, respectively, and $S_{c}$ and $S_{s c}$ denote the corresponding maximum allowable values.

The next two constraints limit the value of the average shear stress in the web, and the corresponding limit state functions can be written as:

$g_{2}(\mathbf{Y})=1-\left|\frac{f_{s}}{S_{s}}\right|$

$g_{3}(\mathbf{Y})=1-\left|\frac{f_{s}^{\prime}}{S_{s}}\right|$

where $f_{s}$ and $f_{s}^{\prime}$ denote the induced shear stress in the left and the clamped end of the beam, respectively, and $S_{s}$ its maximum allowable value.

The tensile stress in the cable must be less than a maximum value. The limit state function in this case is:

$g_{4}(\mathbf{Y})=1-\left|\frac{f_{t}}{S_{t c}}\right|$

where $f_{t}$ is the cable stress and $S_{t c}$ is its maximum allowable value.

Finally, the maximum vertical deflection of the beam, $\delta_{u}$, is restricted to be less than a maximum value $\delta_{\max }$. Therefore, the limit state function for this constraint can be written as: 
$g_{5}(\mathbf{Y})=1-\frac{\delta_{u}}{\delta_{\max }}$

The optimization problem has been solved by using a sequential unconstrained minimization algorithm. The NEWSUMT-A computer program has been used. Details about this program can be found in $[16,17]$.

Most optimizers first determine a direction and then minimize the objective function in that direction. This is called One Dimensional Minimization (O.D.M.). NEWSUMT-A in particular is based on a quadratic extended penalty function and Newton's method for unconstrained minimization. More specifically, an augmented objective function is used:

$\phi(\mathbf{Y}, r)=F(\mathbf{Y})+r \sum_{i=1}^{n} p\left(g_{i}\right)$

where $\mathrm{r}$ is a penalty parameter and $p\left(g_{i}\right)$ is a function associated with the ith constraint.

The solution to the optimization problem is obtained by minimizing the function $\phi$, for a decreasing sequence of $r$ values. For each value of $r$ one unconstrained minimization is performed.

In the present work when we use the original SIO approach only one call of NEWSUMT-A is made and we perform exact evaluation of reliability for each O.D.M. When the first approximate method is used two calls of NEWSUMT-A are made. The first time we perform one unconstrained minimization with exact 
evaluation of reliability for each O.D.M. The second we perform approximate evaluation of reliability for each O.D.M. When the second approximate method is used, two calls of NEWSUMT-A are made again. This time for the first call we perform three or four unconstrained minimizations, according to the specific case, with exact evaluation of reliability for each O.D.M. Then the second call is made and we use approximate evaluation of reliability for each O.D.M.

In most of the following Method 1 refers to the SIO approach including the semi-analytical formulas for the sensitivity derivatives, Method 2 to the first ASIO method described in Section 4.2, and Method 3 to the second ASIO method described in section 4.3. Also in the following by one complete iteration we denote a complete unconstrained minimization (corresponds to one response surface of NEWSUMT-A).

\subsection{Effect of Semi-analytical Sensitivity Analysis.}

At this point the results obtained from the original SIO approach are compared to those obtained by the same method, but after using semi-analytically calculated derivatives, instead of derivatives evaluated by finite differences. The results for all five case are presented in Tables 2 through 6 . In these tables method 1 refers to the original SIO approach without sensitivity analysis, whereas method 2 refers to the original SIO approach with sensitivity analysis. The initial design vector is: $X_{1}=2.0, X_{2}=3.0, X_{3}=5.0$. We observe 
that for all five cases and all probabilities of survival the values of the objective function are almost identical for both methods. This validates the accuracy of the semi-analytical formulas for sensitivity analysis.

In the same tables the percentage of reduction in time is also presented. We notice that in about $80 \%$ of the cases we have a significant reduction in the computational time (more than $30 \%$ ). This should be expected, since we no longer use finite differences, which are very expensive, to evaluate the sensitivity derivatives. In all but one of the remaining cases a reduction in the computational time of the order of one to $30 \%$ can still be observed.

In one case, which corresponds to a prescribed failure probability of 0.5 an increase in the computational time was observed (Table 2). For this limiting case the failure surface passes through the origin, because the required safety index is 0 . Therefore, the point corresponding to the mean values of the random variables coincides with the most probable failure point. Consequently, the FOSM method, expanding around the means of the random variables, yields identical results with the AFOSM method and the iterations performed there are unnecessary. The aforementioned result is most probably caused by numerical peculiarities of the iterative method itself and is not considered a weakness of the method. This is verified from the fact that for a different initial design point we got a reduction in computational time for this case comparable to the rest of the cases. Even in this case, though, the accuracy of the results at the optimum is not affected. Thus, we may conclude that in most of the cases use of 
semi-analytically evaluated sensitivity derivatives will result in a significant reduction in the computational time.

\subsection{Validation of the Optimization Procedure}

In order to test the accuracy and the robustness of the two variants of the ASIO approach, we used them to optimize the same structure starting from several different initial values of the design variables, and we compared the final optimum design to that obtained from the original SIO approach.

The data of the problem are the same for all three methods and are the ones presented in Table 1. The final values of the objective function for each case are presented in Tables 7 through 11 . The initial point was: $X_{1}=2.0, X_{2}=3.0$, $X_{3}=5.0$. Method 3 did not converge to the correct optimum, unless a few complete iterations of the original SIO method had been performed first, in order to obtain a good starting point. The results presented here are obtained for three complete iteration cycles of the original SIO approach before the actual approximate method is applied, except where it is stated differently. For Method 2 we performed one complete iteration of the original SIO approach, before applying the approximate method.

As it can be observed the First Method of the ASIO approach gives almost identical results with the original SIO approach, in almost every case. The largest difference is observed for Case 4 and for safety index $\beta=2.33$ and is about 
$0.16 \%$. For the Second Method of the ASIO approach and for three complete outer loop iterations before the actual approximate method can be applied, we got maximum differences between the values of the objective function, for each case in the range from $0.31 \%$ to $1.15 \%$. The same accuracy, as for the objective function, was observed for the values of the design variables at the optimum, as well. The values of the objective function, at the end of each unconstrained minimization for two of the methods, for Case 3 and safety index 2.33 are presented in Fig. 8. We observe that the values of the objective function drop similarly for both methods. For the same Case and safety index the change of the safety index every unconstrained minimization, for each failure mode, is presented in Fig. 9-11. Here, we can observe how the safety index drops in every unconstrained minimization, until it reaches its limiting value of 2.33 , at the optimum, for the critical constraints.

We note at this point that, in many cases, even for two complete iterations for the Second Method of the ASIO approach we got reasonable results, but the difference in the values of the objective function, between the above method and the original SIO approach was higher, in some cases being about $5 \%$. That is why the option of performing three complete iteration cycles was preferred.

It becomes clear that we can obtain accurate results with the integrated analysis and design methods. The accuracy of the original SIO approach has been investigated in [7], by comparing the results of the SIO approach to the results obtained by Monte-Carlo simulation. The SIO approach proved to be reasonably accurate, even for high uncertainties of the parameters involved. 
In order to get an idea about the robustness of the two ASIO methods, we ran all five cases in Table 1 for a prescribed value of the safety index of 2.33, starting with different values of the initial design vector; and we compared the results to those obtained by the SIO Method. The results we got are presented in Tables 12 through 16. As we can see most of the results show good agreement. The greater differences between values are observed for the web thickness, and they are due to the fact that this variable is in most cases an order of magnitude smaller than the rest of the design variables. Consequently the value of that variable does not affect the value of the objective function by much. Since the convergence of the value of the objective function is one of the main criteria of convergence of the whole optimization algorithm, we may obtain optimal designs with about the same value of the objective function, but considerable difference in the values of the web thickness.

\subsection{Optimization Results}

The optimum design has been obtained for each of the three methods, for values of the required probability of survival in the range from $0.5(\beta=0)$ to $0.9999(\beta=3.72)$. Five cases have been studied. The values of the coefficients of variation of the random parameters in each of the cases are shown in Table 1. The outer loop of optimization step was iterated to full convergence. As we showed in the previous section, the final design converged to very similar values 
for the three methods used, demonstrating the feasibility of integrating the analysis and design in the reliability based optimization, using a safety index approach.

A comparison of the computational time required to achieve full convergence for each case and probability of survival, for the three methods is presented in Tables 17 through 21 .

As we can observe, significant savings in computational time can be achieved. We note that the savings appearing here reflect only the effect of integrating the analysis and design. In more than $80 \%$ of the cases the First Method of ASIO gave savings in computational time of $40 \%$ or better. In the remainder of the cases it gave savings of $15-40 \%$ The Second method of the ASIO approach gave savings of $40 \%$ or better in $71 \%$ of the cases, while in the remainder of the cases the savings were between 33 and $40 \%$.

Next, we wanted to get an idea on how the computational time breaks down to that required for various tasks. To achieve that, we examined the results obtained from the five cases and for safety index 2.33 . The results are presented in Tables 22-23. We compared the following methods:

- Original SIO (Method 1).

- SIO with sensitivity analysis (Method 2).

- First ASIO Method (Method 3). 
- Second ASIO Method (Method 4).

We used the number of O.D.M. as a measure of comparison. This number shows how many searches the optimizer performs during the optimization procedure. It can be observed, from Table 22, that the O.D.M. time for SIO with sensitivity analysis is the highest among all methods, while the time used for direction finding is significantly higher for the original SIO approach, than for the rest of the methods. Consequently, we can conclude that the main achievement of all the approximate methods, introduced in the present work, is to reduce the direction finding time for the optimization procedure.

Concerning the number of analyses, by looking at the number of O.D.M. and the numbers of approximate objective functions, constraints and approximate constraint functions we can see that we need a greater number of analyses for the First ASIO method than for the original SIO method. This is not an unusual result, since the optimizer is expected to converge at a slower pace, when we reduce the accuracy in the calculated constraint values at each step of optimization, by introducing approximations. The same trend was not observed, though, for the Second ASIO method. The time required to evaluate the constraints is significantly reduced, if we use the two variants of the ASIO approach.

Finally, we wanted to examine how the computational time is affected, if instead of starting from an arbitrary initial design point, we start from a design point close to the final one. In order to achieve that, we used as an initial design point the point obtained from the original SIO method after two complete 
iterations and we ran all three methods again. In this case we performed only one complete iteration cycle for Method 3. The values of the objective function for all the cases are presented in Tables 24-28. The computational times are given in Tables 29-33.

First, we observed in this case that use of semi-analytically calculated sensitivity derivatives had a much lesser effect on the computational time. On the other hand the savings in computational effort, achieved by implementing the ASIO approaches, were larger than those in Tables 17-21. A typical diagram of the savings obtained, by using the ASIO methods is presented in Fig. 12. There, the computational time for each method is presented for Case 5 and probability of survival 0.9. More specifically, the First ASIO method gave savings of $60 \%$ or better for most of the cases. In all the rest but three of the cases the savings were between 50 and $60 \%$. The Second ASIO method gave better savings ranging from 64 to $76 \%$. We note, though, that the Second Method did not converge in all cases. That instability was mainly observed for higher coefficients of variation and higher probabilities of survival.

The above results can lead to the conclusion that the ASIO methods considerably reduce the computational time, especially in the final stages of the optimization procedure.

By comparing the two new approximate methods we may draw as a general conclusion, that Method 2 is almost always accurate resulting in significant savings, in terms of computational time. Method 3 usually results in greater savings in computational time, but it is probable that its accuracy and stability 
will depend on each specific problem, so that some study of the specific case may have to be performed, before this method can be applied. The rest of the advantages of the SIO approach over the $\mathrm{CCP}$ technique are expected to still hold.

The aforementioned percentages of savings in computational time may represent significant reduction in the computational time, in absolute numbers in the cases of complicated examples, with a lot of design variables. Use of the original SIO approach in such cases would be inefficient otherwise.

In order to apply the approximate methods to a practical, real life problem the first thing we could do is check if the optimum satisfies the conditions for a local minimum. We can also take the final design point, obtained by any of the two variants of the ASIO approach, and run a few cycles of the original SIO method using the above point as the initial design point. If the original SIO method converges to the same point, then this is an indication that the ASIO method works for the specific problem. Otherwise, another combination of the number of iterations in each loop of the ASIO method can be examined.

It should be noted that it is very common in real life problems to have an idea on where the optimum is. So, we very seldom start from a point too far away from the optimum. This fact makes the approximate methods introduced in this work even more applicable to real life situations. Consequently, use of the ASIO methods may enable us to apply of the SIO approach in real life design problems, without the excessive computational cost required by the original SIO method. 


\section{Chapter 6}

\section{Conclusions}

When reliability based optimization is performed, using a safety index approach, via an iterative solution technique, it is possible to integrate the analysis and design iterations. Two variations of the original SIO approach were presented.

The optimization of a cable stayed box girder was studied as an example. The structure was optimized so as to minimize its cost. Both of the approximate methods were validated, by comparing their results to the results obtained by the original SIO approach. Good agreement was observed in both cases. The robustness of both approximate methods was also examined and the results were satisfactory.

The integrated analysis and design methods presented here are based on partially converged iteration loops of the whole iterative procedure. The following are the main conclusions from our study: 
1. The computational time can be significantly reduced, with only minimal effects on the final design.

2. The effect of using semi-analytical methods instead of finite-differences to evaluate the sensitivity derivatives was also demonstrated. Significant savings were observed again.

3. The methods, as presented here, are flexible and can be directly applied to any complex problem, involving any number of design variables. However, the stability and accuracy of the methods in such cases will have to be explored.

4. The robustness of the ASIO was found to be satisfactory in the cases studied.

Future research should be directed towards the investigation of the generality of the above algorithms. More complicated examples, involving a large number of design variables and possibly finite element analyses of the structure should be studied, in order to investigate applicability of the methods proposed here to practical design problems. 


\section{Bibliography}

[1] Fred Moses and David E. Kinser, "Optimum Structural Design with Failure Probability Constraints " , AIAA Journal Vol 5., No 6, 1966.

[2] Thoft-Christensen, P. and Sorensen, J.D., " Reliability Analysis of Elasto-Plastic Structures ", IFIP Conference on System Modelling and Optimization, Proc. 11, 1984

[3] Sorensen, J.D. and Thoft-Christensen, P., " Structural Optimization with Reliability Constraints ", IFIP Conference on System Modelling and Optimization, 1985

[4] Feng, Y.S., and Moses, F., "A Method of Structural Optimization Based on Structural System Reliability", J. Struct. Mech. , Vol. 14, No. 4, pp.437-453, 1986.

[5] Feng, Y.S., and Moses, F., " Optimum Design , Redundancy and Reliability of Structural Systems ", Computers and Structures, Vol. 24, No. 2, pp.239-251,1986.

[6] S.S.Rao," Structural Optimization by Chance Constraint Programming Techniques ", Computers and Structures, Vol. 12, pp. 778-781, 1980.

[7] E.Nikolaidis, R.Burdisso,“ Reliability Based Optimization: A Safety Index Approach ”, Computers and Structures, Vol. 28, No. 6, pp.781-788, 1988.

[8] Frangopol, D.M., “ Interactive Reliability-Based Structural Optimization”, Computers and Structures, Vol. 19, No. 4, pp.559-563, 1984. 
[9] Frangopol, D.M., " Sensitivity of Reliability-Based Optimum Design ", Journal of Structural Engineering, Vol. 111, No. 8, pp. 1703-1721, 1985.

[10] Rao S.S., " Automated Optimum Design of Wing Structures: A Probabilistic Approach ", Computers and Structures, Vol. 24, No. 5, pp. 799-808, 1986.

[11] Byung Man Kwak and Tae Won Lee, "Sensitivity Analysis for Reliability Based Optimization Using an AFOSM method", Computers and Structures , Vol. 27, No. 3, pp. 399-406, 1987.

[12] J.D.Sorensen, " Reliability Based C timization of Structural Systems ", ISSN , 0902-7513 R8718, 1987.

[13] Pinkster, J.A. et al., “ Stochastic Modelling ", Report of Committee V. 6 , 10th International Ship and Offshore Structures Congress, Denmark 1988.

[14] Haftka, R.T. and Kamat M.P., " Simultaneous Non-linear Analysis and Design ”, Computational Mechanics, Vol. 4, No. 6, pp. 409-416, 1989.

[15] R.T. Haftka, "Integrated Non-linear Structural Analysis and Design ", AIAA Paper $88-2380$, presented at the 29th AIAA/ASME/ASCE/AHS Structures, Structural Dynamics and Materials Conference, Williamsburg, Virginia, April 18-20, 1988.

[16] B. Barthelemy, R.T. Haftka, U. Madapur and S. Sankaranarayanan, “ Integrated Analysis and Design Using 3-D Finite Elements ", AIAA Paper 89-1309 , Proceedings AIAA/ASME/ASCE/AHS/ASC 30th Structures, Structural Dynamics and Materials Conference, Mobile, Alabama, April 3-5, 1989, Part 3, pp. 1305-1310.

[17] C.A.Cornell, “ A Probability-Based Structural Code ”, J. Am. Concr. Inst. , No. 66, pp.974-985, 1969.

[18] A.Charnes and W.W.Cooper, "Chance Constrained Programming", Mgmt. Sci. , Vol. 6, 73-79, 1959.

[19] J.W.Davidson, L.P.Davidson,L.P.Felton, and G.C.Hart, “ Optimum Design of Structures with Random Parameters", Computers and Structures, Vol. 7, pp.481-486, 1977

[20] S.F.Jozwiak, “ Minimum Weight Design of Structures with Random Parameters ", Computers and structures, Vol. 23, pp.481-485, 1986.

[21] A.M.Hasofer and N.C.Lind, "Exact and Invariant Second Moment Code Format ", J. Engng. Mech. Div. ASCE, Vol. 100, pp.111-121, 1974. 
[22] A.H-S. Ang and W.H.Tang, "Probability Concepts in Engineering Planning and Design ", Vol. 2, pp. 333-347, John Wiley, New York, 1984.

[23] H.O.Madsen, S.Krenk and N.C.Lind, " Methods of Structural Safety", Prentice-Hall, Englewood Cliffs, NJ, 1986.

[24] Pei-Ling Liu, Armen Der Kiureghian, “ Optimization Algorithms for Structural Reliability Analysis ”, Report No. UCB/SESM- 86/09, 1986.

[25] Rajiv Thareja and R.T.Haftka, "NEWSUMT-A: A Modified Version of NEWSUMT for Inequality and Equality Constraints" , Aerospace and Ocean Engineering Department, VPI\&SU, March 1985.

[26] R.V.Grandhi, R.Thareja and R.T.Haftka, "NEWSUMT-A: A General Purpose Program for Constrained Optimization Using Constraint Approximations," , ASME, J. Mech. Transmiss. Automat. Des. , Vol. 107, pp. 94-99, 1985. 


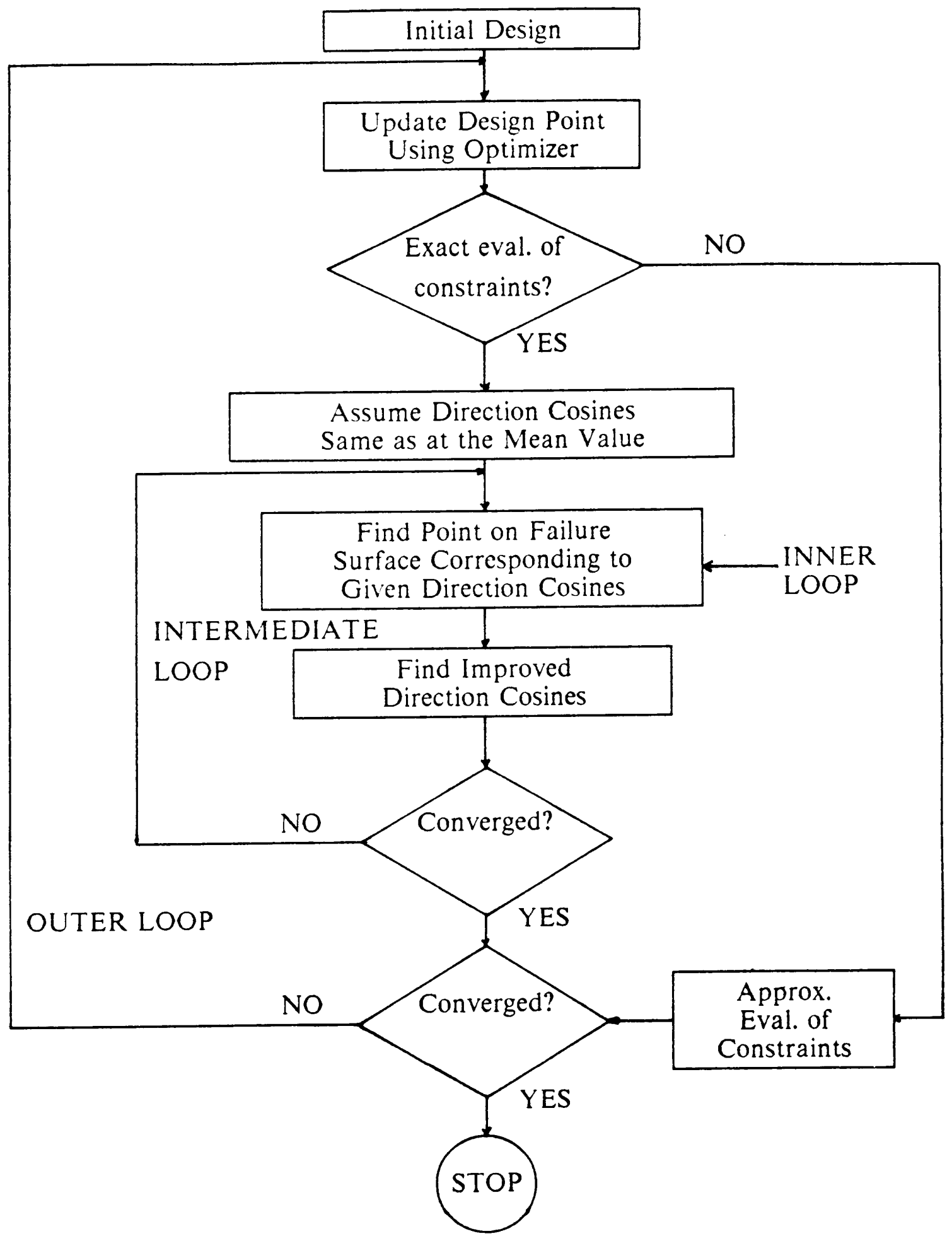

Figure 1. Flow-chart for Original SIO Method. 


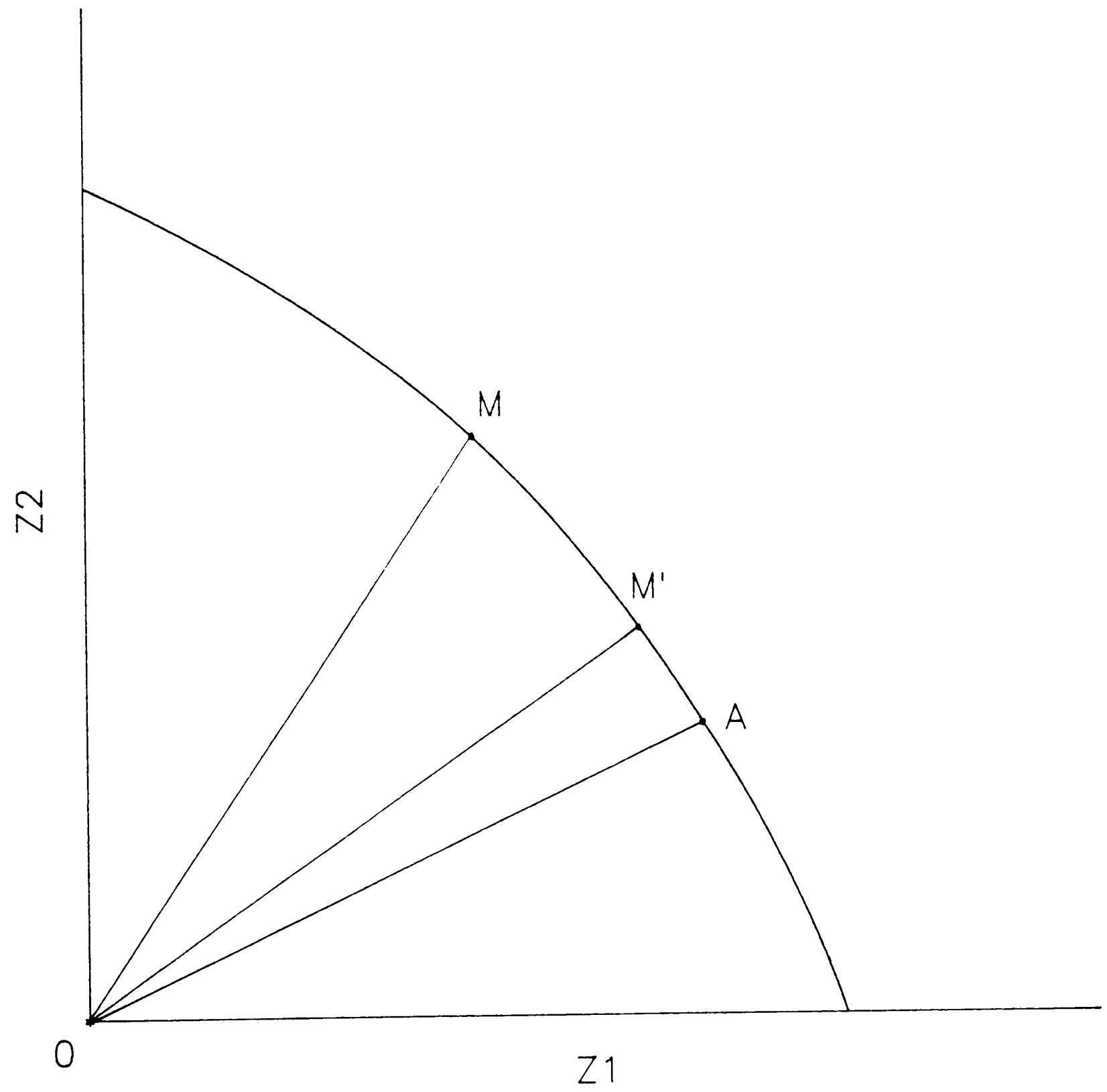

Figure 2. Iterative procedure for Original SIO method. 


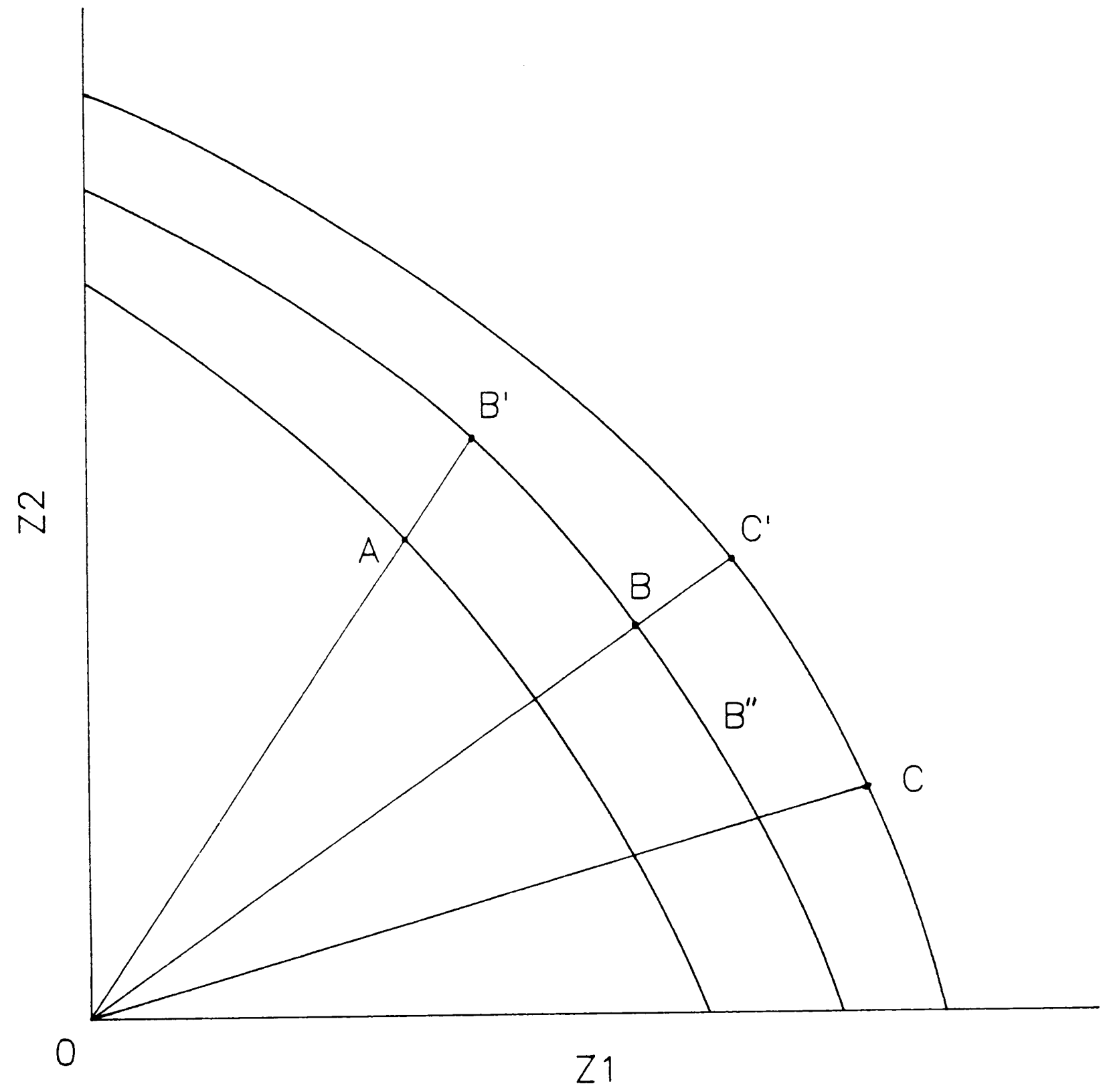

Figure 3. Iterative procedure for the First ASIO Method. 


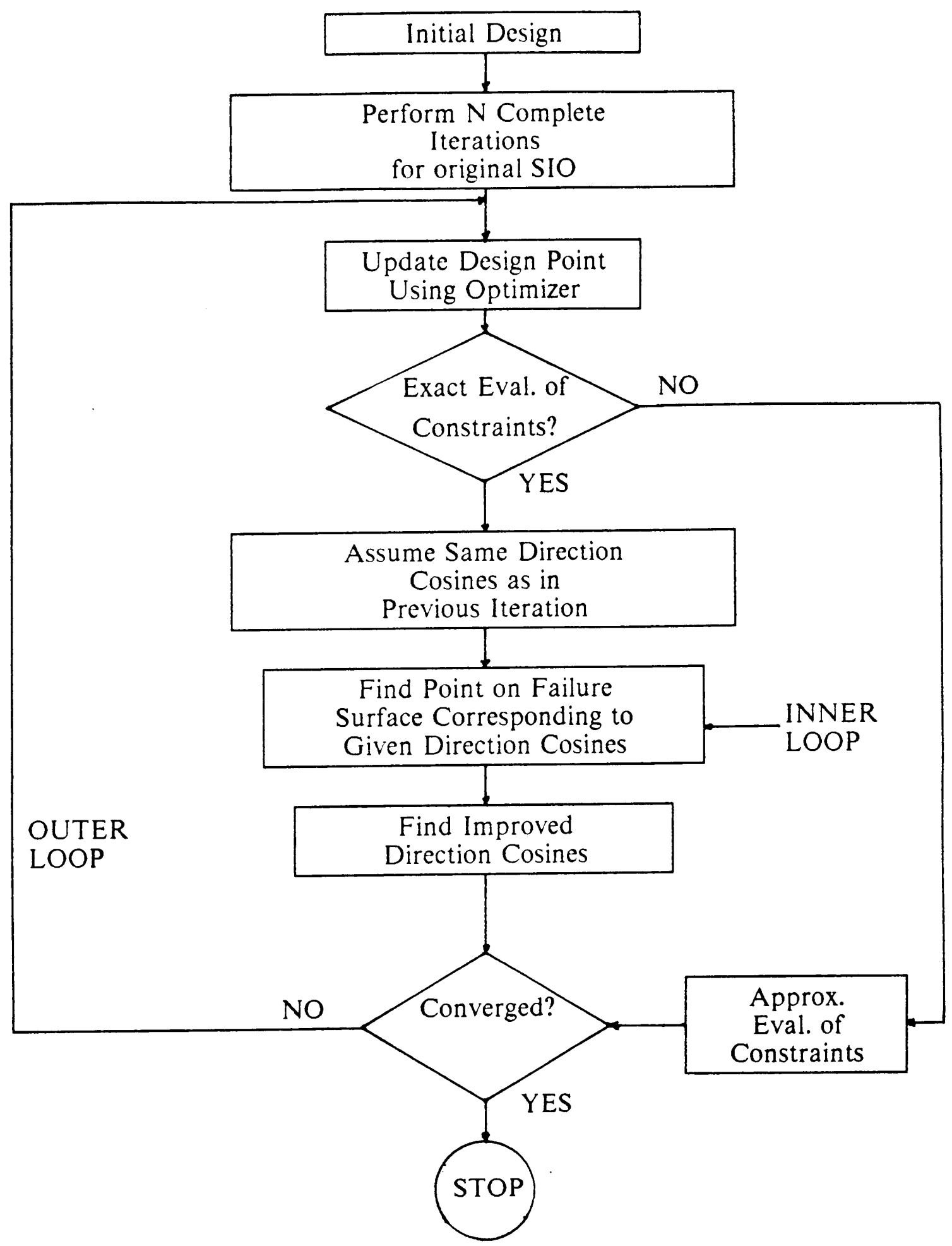

Figure 4. Flow-chart for the First ASIO Method. 


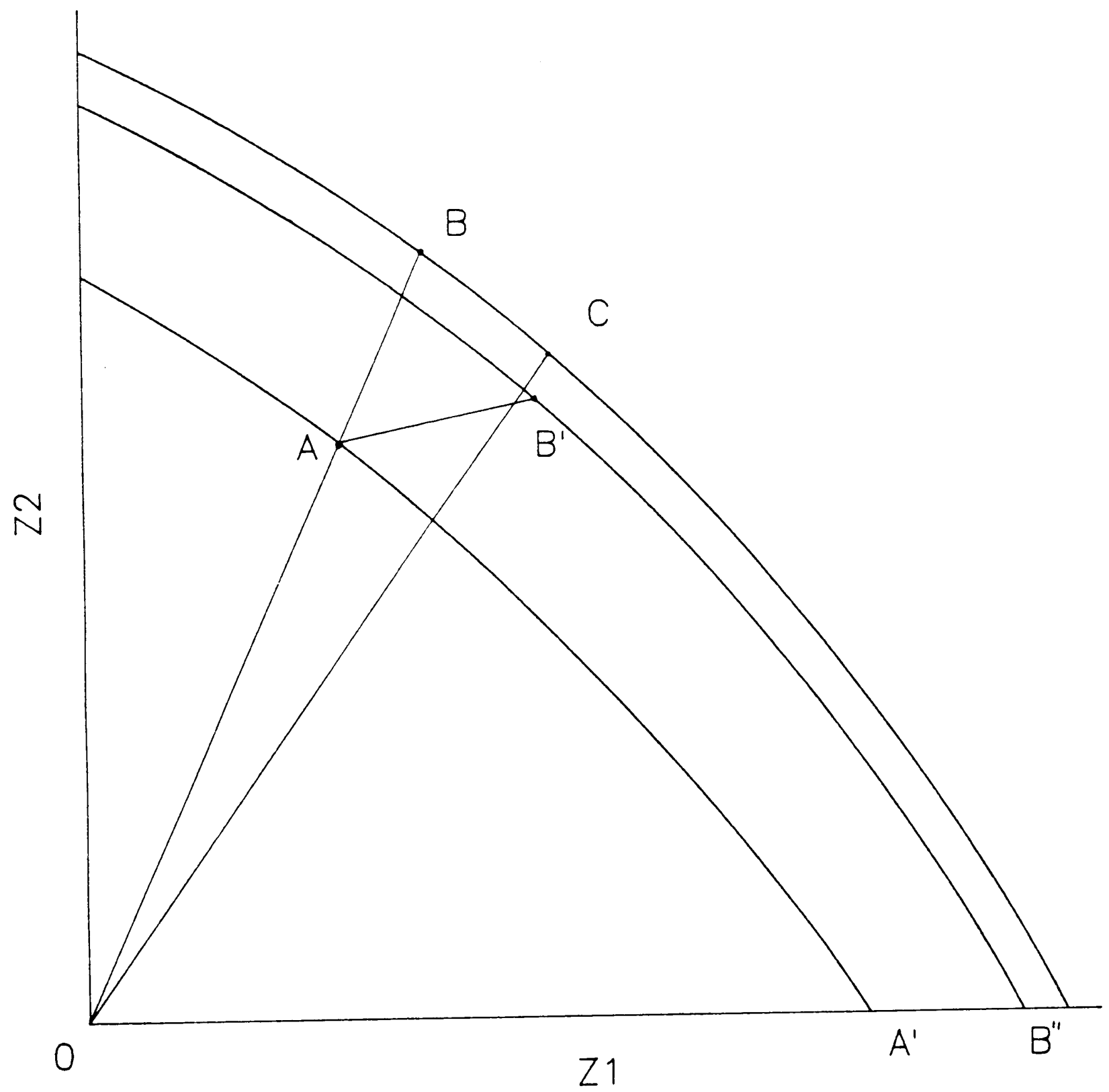

Figure 5. Iterative procedure for the Second ASIO Method. 


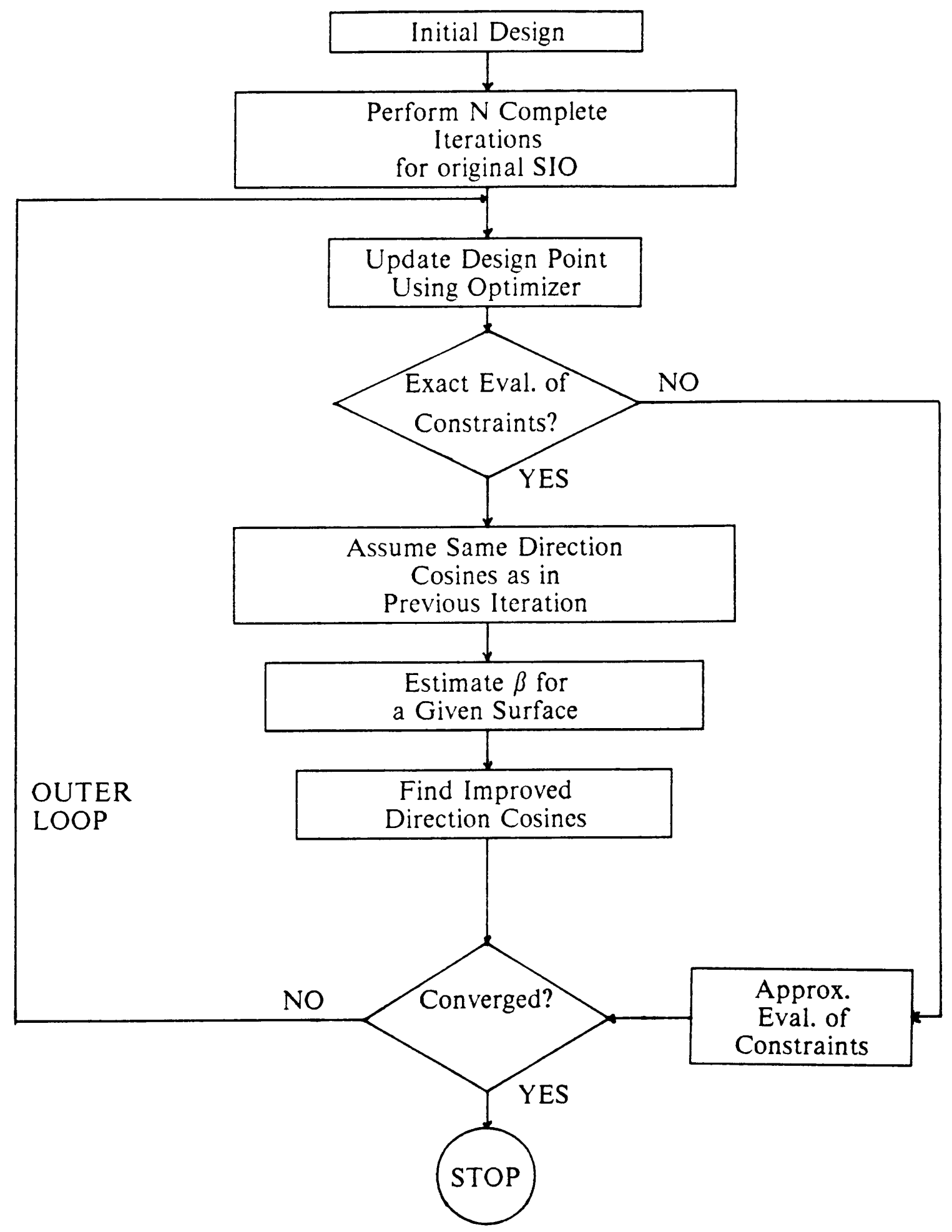

Figure 6. Flow-chart for the Second ASIO Method. 

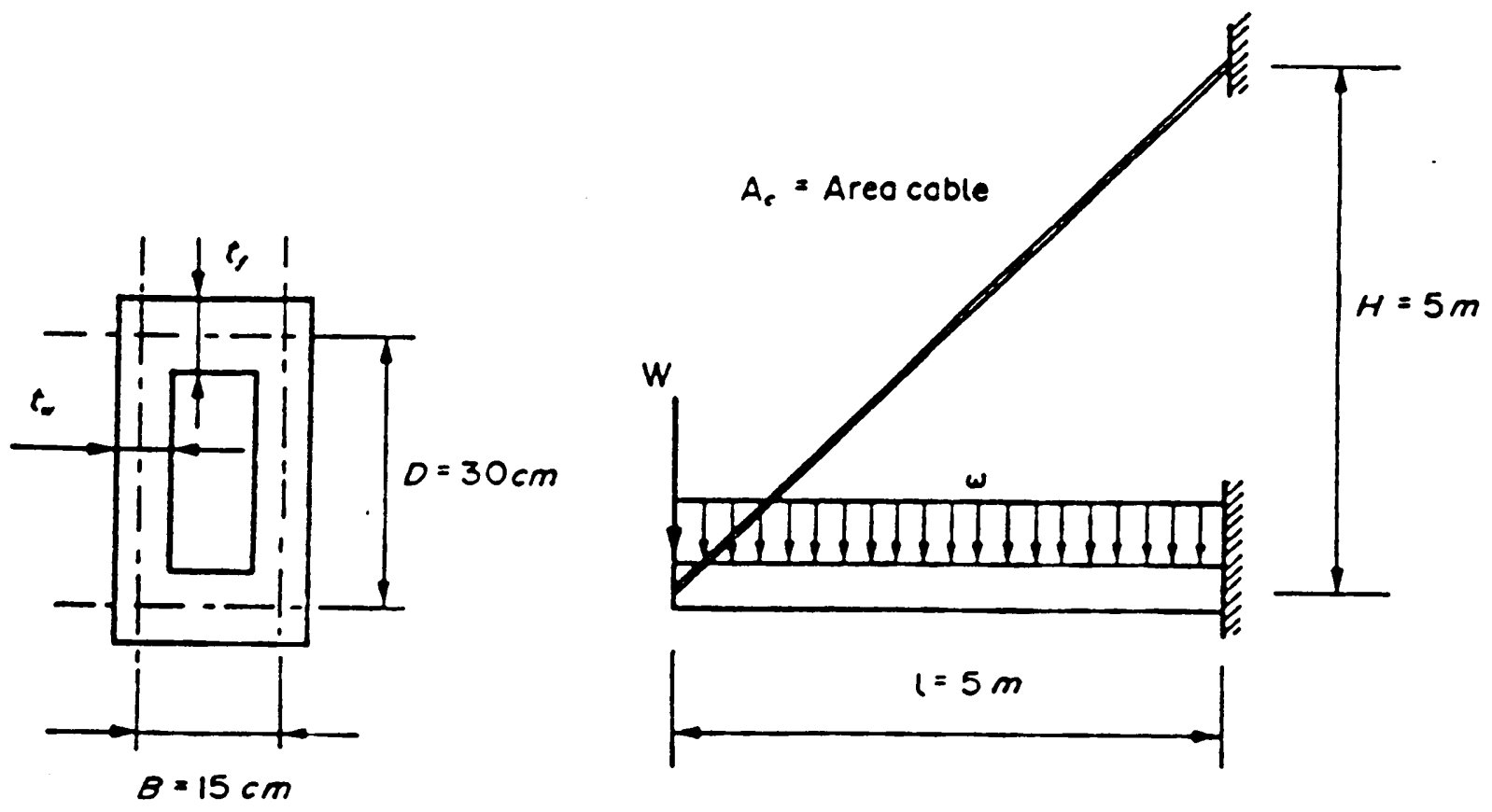

Figure 7. Cable stayed cantilevered box-beam. 


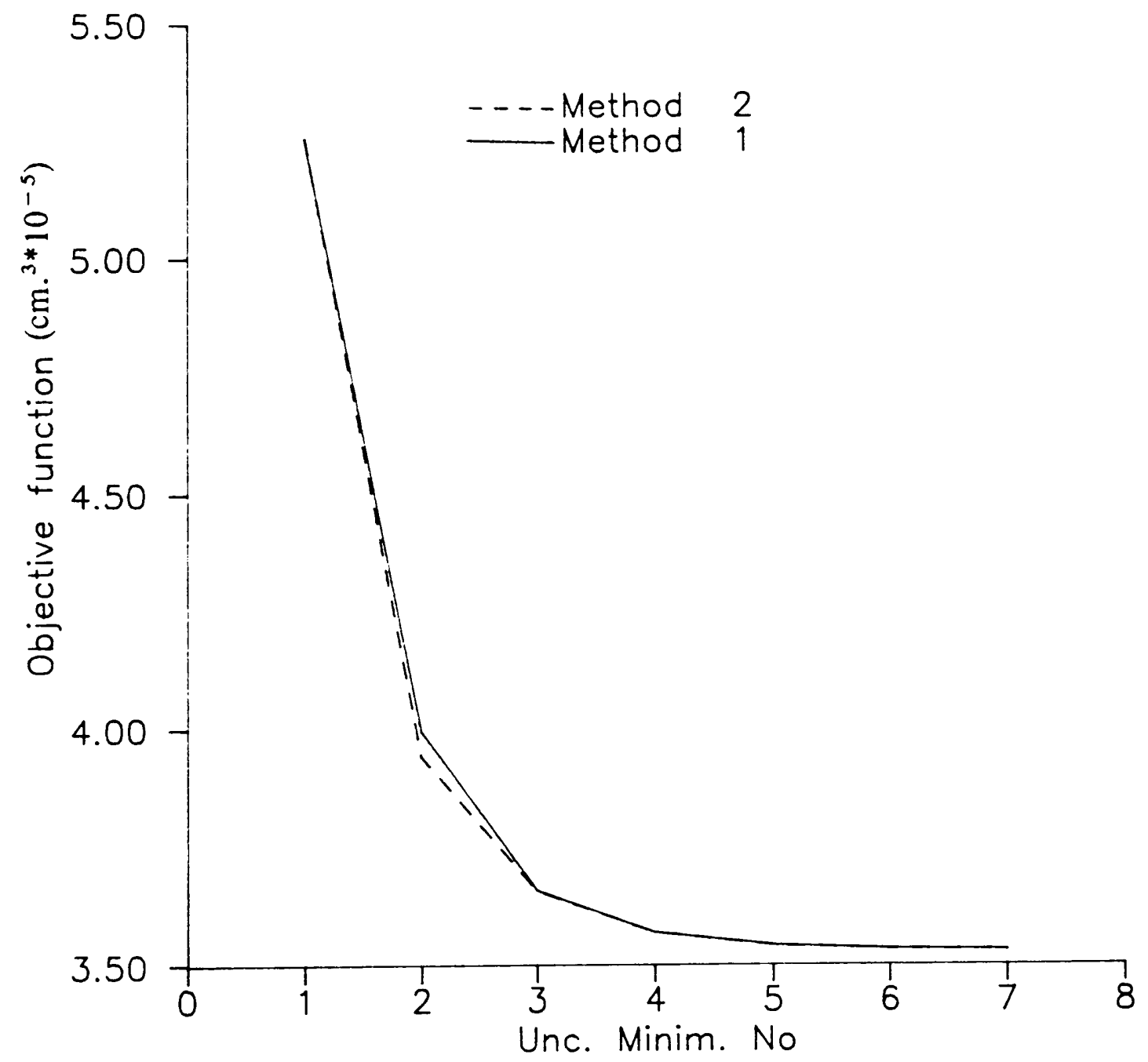

Figure 8. Objective function for each iteration, for Case 3 and $\beta=2.33$. 


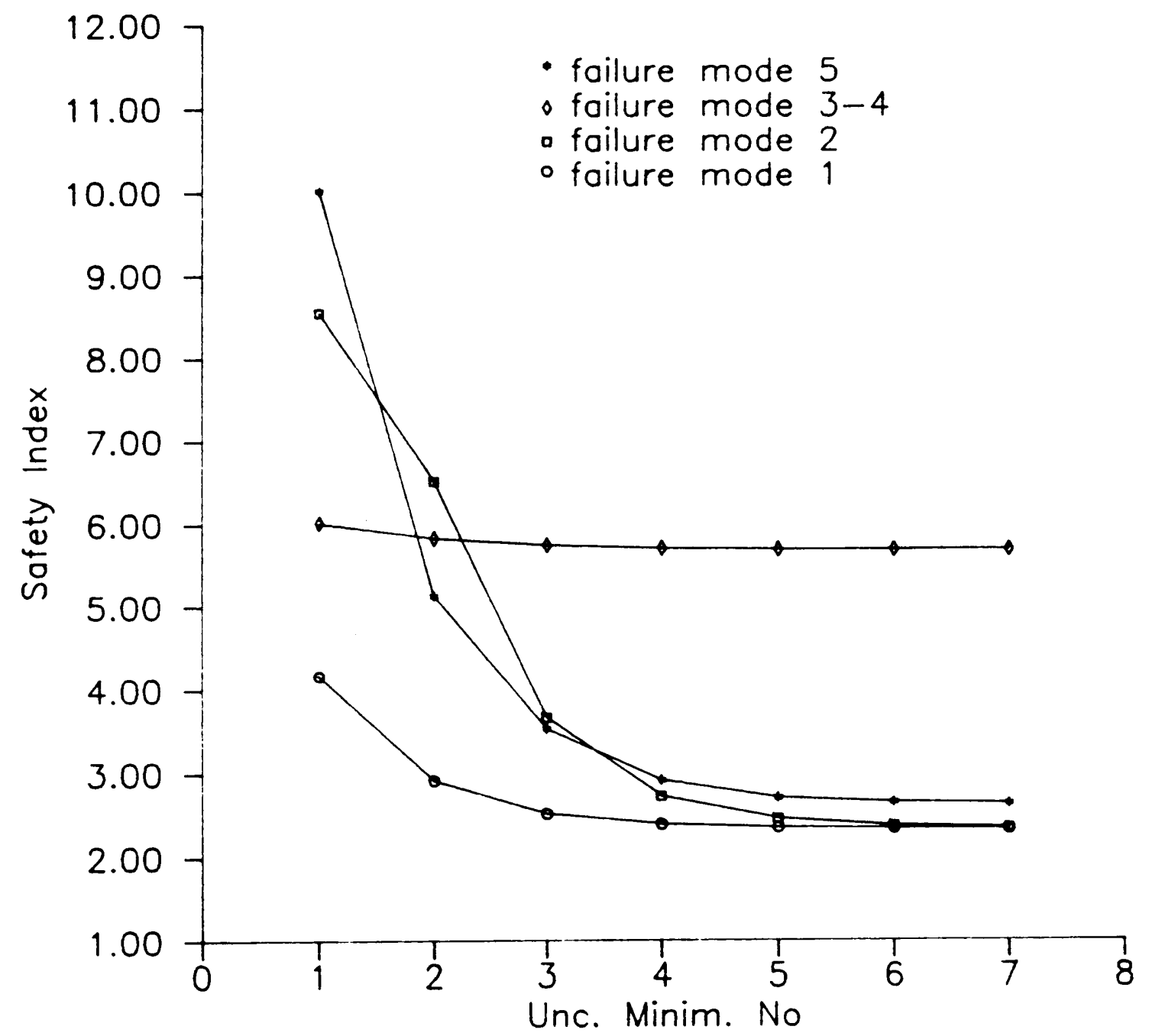

Figure 9. Safety index for each iteration, for Case 3 and $\beta=2.33$. Method 1 . 


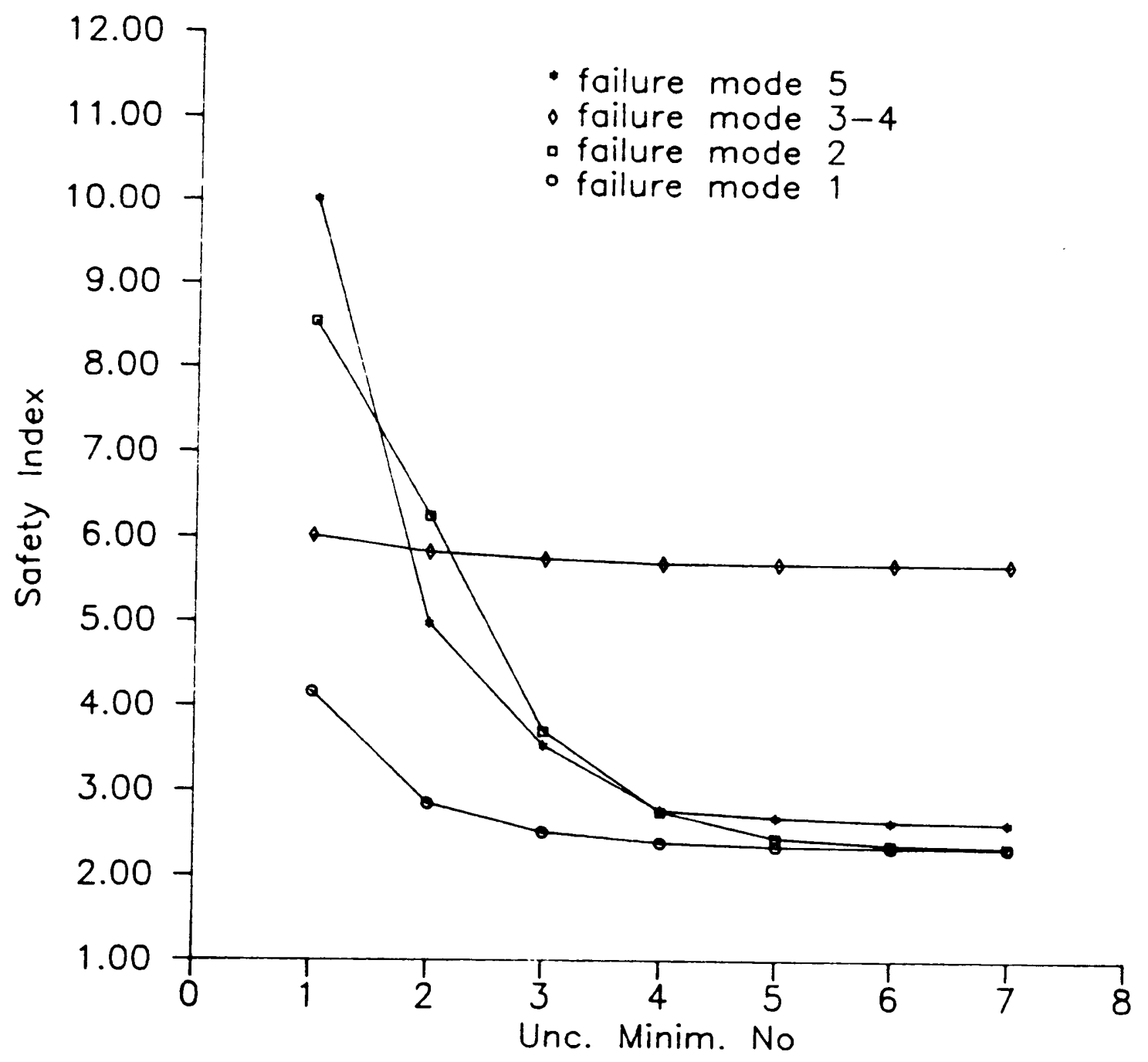

Figure 10. Safety index for each iteration, for Case 3 and $\beta=2.33$. Nethod 2 . 


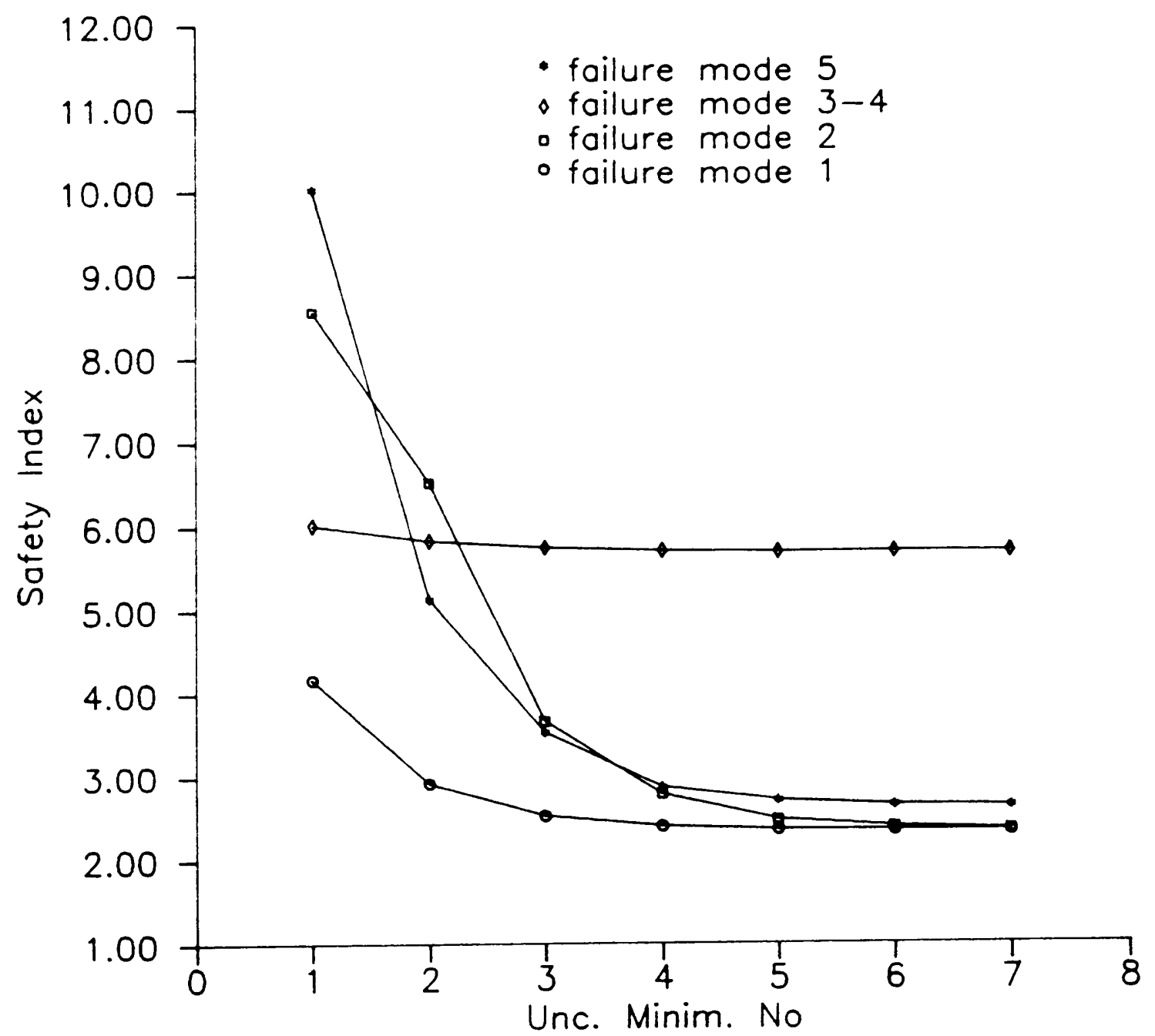

Figure 11. Safety index for each iteration, for Case 3 and $\beta=2.33$. Method 3 . 


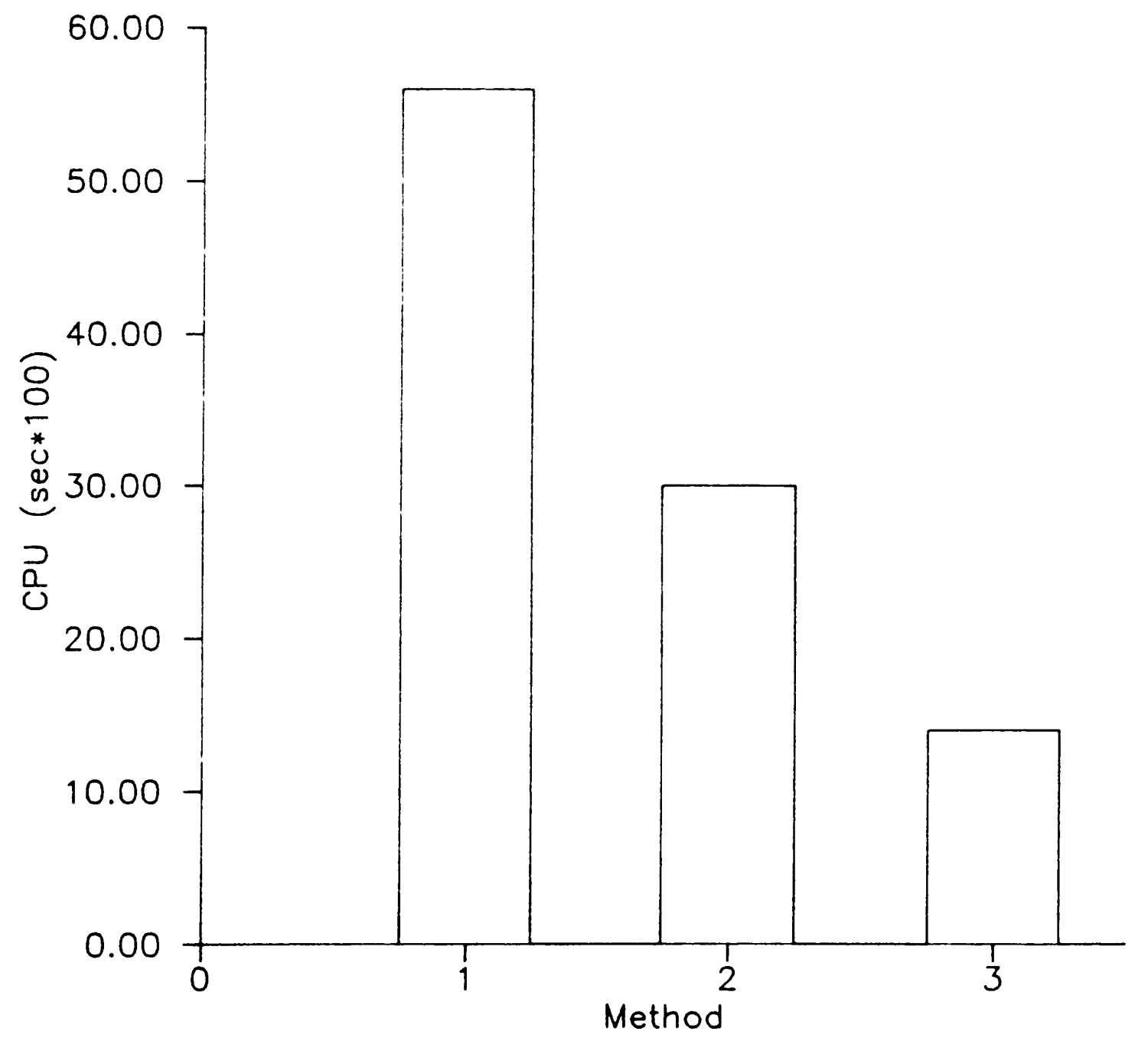

Figure 12. CPU time for the three methods, for Case 5 and $\beta=1.28$. 
Table 1. Random parameters and their statistics.

\begin{tabular}{|c|c|c|c|c|c|c|}
\hline & & $\mathrm{Coc}$ & ficient $o$ & variation & $(\mathrm{CV})$ & \\
\hline Parameter & Mean & Case 1 & Case 2 & Case 3 & Case 4 & Case 5 \\
\hline Conc. load & $408,000 \mathrm{~N}$ & 0.01 & 0.05 & 0.1 & 0.15 & 0.20 \\
\hline Distr. load & $80,000 \mathrm{~N} / \mathrm{m}$ & 0.01 & 0.05 & 0.1 & 0.15 & 0.20 \\
\hline $\begin{array}{l}\text { Max. bending } \\
\text { comp. stress }\end{array}$ & $157.5 \mathrm{MPa}$ & 0.01 & 0.05 & 0.1 & 0.15 & 0.20 \\
\hline $\begin{array}{l}\text { Max. direct } \\
\text { comp. stress }\end{array}$ & $125.59 \mathrm{MPa}$ & 0.01 & 0.05 & 0.1 & 0.15 & 0.20 \\
\hline $\begin{array}{l}\text { Max. shear } \\
\text { stress }\end{array}$ & $94.5 \mathrm{MPa}$ & 0.01 & 0.05 & 0.1 & 0.15 & 0.20 \\
\hline $\begin{array}{l}\text { Max. cable } \\
\text { stress }\end{array}$ & $1200.0 \mathrm{MPa}$ & 0.075 & 0.15 & 0.15 & 0.20 & 0.20 \\
\hline Web thickness & ---- & 0.001 & 0.005 & 0.01 & 0.015 & 0.02 \\
\hline $\begin{array}{l}\text { Flange } \\
\text { thickness }\end{array}$ & ---- & 0.001 & 0.005 & 0.01 & 0.015 & 0.02 \\
\hline $\begin{array}{l}\text { Cable sect. } \\
\text { area }\end{array}$ & --- & 0.001 & 0.005 & 0.01 & 0.015 & 0.02 \\
\hline
\end{tabular}


Table 2. Comparison of Computational Time between original SIO (1) and SIO with sensitivity analysis (2) Methods. Case 1 .

\begin{tabular}{|ccccc|}
\hline $\begin{array}{c}\text { Prob. Surv./ } \\
\text { Saf. Index }\end{array}$ & Method & $\begin{array}{c}\text { Obj. Function } \\
\left(\mathrm{cm} .^{\left.3 * 10^{-5}\right)}\right.\end{array}$ & $\begin{array}{c}\text { CPU Time } \\
\left(\text { Sec. }^{* 100)}\right.\end{array}$ & $\begin{array}{c}\text { Time Reduct. } \\
(\%)\end{array}$ \\
$0.5 / 0.0$ & 1 & 2.576 & 63 & \\
& 2 & 2.576 & 70 & -11.11 \\
$0.84 / 1.0$ & 1 & 2.607 & 67 & \\
& 2 & 2.607 & 59 & 11.94 \\
$0.9 / 1.28$ & 1 & 2.616 & 67 & \\
& 2 & 2.616 & 59 & 11.94 \\
$0.95 / 1.65$ & 1 & 2.627 & 68 & \\
& 2 & 2.627 & 59 & 13.24 \\
$0.99 / 2.33$ & 1 & 2.649 & 68 & \\
& 2 & 2.649 & 59 & 13.24 \\
$0.999 / 3.10$ & 1 & 2.674 & 65 & \\
& 2 & 2.674 & 59 & 9.23 \\
$0.9999 / 3.72$ & 1 & 2.694 & 68 & 11.76 \\
& 2 & 2.694 & 60 & \\
\hline
\end{tabular}


Table 3. Comparison of Computational Time between original SIO (1) and SIO with sensitivity analysis (2) Methods. Case 2.

\begin{tabular}{|ccccc|}
\hline $\begin{array}{c}\text { Prob. Surv./ } \\
\text { Saf. Index }\end{array}$ & Method & $\begin{array}{c}\text { Obj. Function } \\
\left(\mathrm{cm} .{ }^{*}{ }^{*} 10^{-5}\right)\end{array}$ & $\begin{array}{c}\text { CPU Time } \\
(\text { Sec.*100) }\end{array}$ & $\begin{array}{c}\text { Time Reduct. } \\
(\%)\end{array}$ \\
$0.5 / 0.0$ & 1 & 2.576 & 85 & \\
& 2 & 2.576 & 55 & 35.29 \\
$0.84 / 1.0$ & 1 & 2.736 & 85 & \\
& 2 & 2.736 & 56 & 34.12 \\
$0.9 / 1.28$ & 1 & 2.783 & 83 & \\
& 2 & 2.783 & 56 & 32.53 \\
$0.95 / 1.65$ & 1 & 2.849 & 84 & \\
& 2 & 2.849 & 56 & 33.33 \\
$0.99 / 2.33$ & 1 & 2.977 & 89 & \\
& 2 & 2.976 & 58 & 34.83 \\
$0.999 / 3.10$ & 1 & 3.136 & 92 & \\
& 2 & 3.136 & 59 & 35.87 \\
$0.9999 / 3.72$ & 1 & 3.279 & 98 & \\
& 2 & 3.279 & 59 & 39.80 \\
\hline
\end{tabular}


Table 4. Comparison of Computational Time between original SIO (1) and SIO with sensitivity analysis (2) Methods. Case 3.

\begin{tabular}{|ccccc|}
\hline $\begin{array}{c}\text { Prob. Surv./ } \\
\text { Saf. Index }\end{array}$ & Method & $\begin{array}{c}\text { Obj. Function } \\
\left(\mathrm{cm} .{ }^{*}{ }^{*} 10^{-5}\right)\end{array}$ & $\begin{array}{c}\text { CPU Time } \\
\left(\text { Sec. }{ }^{* 100)}\right.\end{array}$ & $\begin{array}{c}\text { Time Reduct. } \\
(\%)\end{array}$ \\
$0.5 / 0.0$ & 1 & 2.576 & 86 & \\
& 2 & 2.576 & 57 & 33.72 \\
$0.84 / 1.0$ & 1 & 2.914 & 89 & \\
& 2 & 2.913 & 58 & 34.83 \\
$0.9 / 1.28$ & 1 & 3.023 & 93 & \\
& 2 & 3.023 & 59 & 36.56 \\
$0.95 / 1.65$ & 1 & 3.181 & 94 & \\
& 2 & 3.181 & 60 & 36.17 \\
$0.99 / 2.33$ & 1 & 3.530 & 92 & \\
& 2 & 3.530 & 59 & 35.87 \\
$0.999 / 3.10$ & 1 & 4.024 & 103 & \\
& 2 & 4.024 & 58 & 43.69 \\
$0.9999 / 3.72$ & 1 & 4.516 & 82 & \\
& 2 & 4.516 & 50 & 39.02 \\
\hline
\end{tabular}


Table 5. Comparison of Computational Time between original SIO (1) and SIO with sensitivity analysis (2) Methods. Case 4.

\begin{tabular}{|ccccc|}
\hline $\begin{array}{c}\text { Prob. Surv./ } \\
\text { Saf. Index }\end{array}$ & Method & $\begin{array}{c}\text { Obj. Function } \\
\left(\mathrm{cm} \text {. }^{\left.3 * 10^{-5}\right)}\right.\end{array}$ & $\begin{array}{c}\text { CPU Time } \\
\left(\text { Sec. }{ }^{* 100)}\right.\end{array}$ & $\begin{array}{c}\text { Time Reduct. } \\
(\%)\end{array}$ \\
$0.5 / 0.0$ & 1 & 2.576 & 93 & \\
& 2 & 2.576 & 54 & 41.94 \\
$0.84 / 1.0$ & 1 & 3.115 & 98 & \\
& 2 & 3.115 & 58 & 40.82 \\
$0.9 / 1.28$ & 1 & 3.309 & 99 & \\
& 2 & 3.309 & 58 & 41.41 \\
$0.95 / 1.65$ & 1 & 3.615 & 100 & \\
& 2 & 3.615 & 54 & 46.00 \\
$0.99 / 2.33$ & 1 & 4.325 & 98 & \\
& 2 & 4.325 & 53 & 45.92 \\
$0.999 / 3.10$ & 1 & 5.486 & 169 & \\
& 2 & 5.485 & 65 & 61.54 \\
$0.9999 / 3.72$ & 1 & 6.900 & 175 & \\
& 2 & 6.899 & 71 & 57.14 \\
\hline
\end{tabular}


Table 6. Comparison of Computational Time between original SIO (1) and SIO with sensitivity analysis (2) Methods. Case 5.

\begin{tabular}{|c|c|c|c|c|}
\hline $\begin{array}{l}\text { Prob. Surv./ } \\
\text { Saf. Index }\end{array}$ & Method & $\begin{array}{l}\text { Obj. Function } \\
\left(\mathrm{cm} \cdot{ }^{3 *} 10^{-5}\right)\end{array}$ & $\begin{array}{l}\text { CPU Time } \\
\left(\text { Sec. }^{*} 100\right)\end{array}$ & $\begin{array}{c}\text { Time Reduct. } \\
(\%)\end{array}$ \\
\hline $0.5 / 0.0$ & $\begin{array}{l}1 \\
2\end{array}$ & $\begin{array}{l}2.577 \\
2.576\end{array}$ & $\begin{array}{l}91 \\
54\end{array}$ & 40.66 \\
\hline $0.84 / 1.0$ & $\begin{array}{l}1 \\
2\end{array}$ & $\begin{array}{l}3.350 \\
3.350\end{array}$ & $\begin{array}{c}102 \\
54\end{array}$ & 45.29 \\
\hline $0.9 / 1.28$ & $\begin{array}{l}1 \\
2\end{array}$ & $\begin{array}{l}3.666 \\
3.666\end{array}$ & $\begin{array}{c}102 \\
56\end{array}$ & 45.09 \\
\hline $0.95 / 1.65$ & $\begin{array}{l}1 \\
2\end{array}$ & $\begin{array}{l}4.172 \\
4.172\end{array}$ & $\begin{array}{l}98 \\
56\end{array}$ & 42.86 \\
\hline $0.99 / 2.33$ & $\begin{array}{l}1 \\
2\end{array}$ & $\begin{array}{l}5.498 \\
5.498\end{array}$ & $\begin{array}{c}125 \\
65\end{array}$ & 48.00 \\
\hline $0.999 / 3.10$ & $\begin{array}{l}1 \\
2\end{array}$ & $\begin{array}{l}8.251 \\
8.251\end{array}$ & $\begin{array}{c}189 \\
91\end{array}$ & 51.85 \\
\hline $0.9999 / 3.72$ & $\begin{array}{l}1 \\
2\end{array}$ & $\begin{array}{l}14.075 \\
14.081\end{array}$ & $\begin{array}{l}97 \\
69\end{array}$ & 38.14 \\
\hline
\end{tabular}


Table 7. Comparison of Objective Function between SIO with sensitivity analysis (1) and ASIO (2 and 3) Methods. Case 1.

\begin{tabular}{|c|c|c|}
\hline Prob. Surv. Saf. Index & Method & Obj. Function $\left(\mathrm{cm} \cdot{ }^{3 *} 10^{-5}\right)$ \\
\hline $0.5 / 0.0$ & $\begin{array}{c}1 \\
2 \\
3(4 \text { iter. })\end{array}$ & $\begin{array}{l}2.576 \\
2.576 \\
2.564\end{array}$ \\
\hline $0.84 / 1.0$ & $\begin{array}{l}1 \\
2 \\
3\end{array}$ & $\begin{array}{l}2.607 \\
2.607 \\
2.596\end{array}$ \\
\hline $0.9 / 1.28$ & $\begin{array}{l}1 \\
2 \\
3\end{array}$ & $\begin{array}{l}2.616 \\
2.616 \\
2.605\end{array}$ \\
\hline $0.95 / 1.65$ & $\begin{array}{l}1 \\
2 \\
3\end{array}$ & $\begin{array}{l}2.627 \\
2.627 \\
2.617\end{array}$ \\
\hline $0.99 / 2.33$ & $\begin{array}{l}1 \\
2 \\
3\end{array}$ & $\begin{array}{l}2.649 \\
2.649 \\
2.639\end{array}$ \\
\hline $0.999 / 3.10$ & $\begin{array}{l}1 \\
2 \\
3\end{array}$ & $\begin{array}{l}2.674 \\
2.674 \\
2.664\end{array}$ \\
\hline $0.9999 / 3.72$ & $\begin{array}{l}1 \\
2 \\
3\end{array}$ & $\begin{array}{l}2.694 \\
2.694 \\
2.685\end{array}$ \\
\hline
\end{tabular}


Table 8. Comparison of Objective Function between SIO with sensitivity analysis (1) and ASIO ( 2 and 3) Methods. Case 2.

\begin{tabular}{|ccc|}
\hline Prob. Surv./Saf. Index & Method & Obj. Function $\left(\mathrm{cm} .^{3 *} 10^{-5}\right)$ \\
& 1 & 2.576 \\
$0.5 / 0.0$ & 2 & 2.576 \\
& 3 & 2.568 \\
& 1 & 2.736 \\
$0.84 / 1.0$ & 2 & 2.736 \\
& 3 & 2.730 \\
& 1 & 2.783 \\
$0.9 / 1.28$ & 2 & 2.783 \\
& 3 & 2.778 \\
& 1 & 2.849 \\
$0.95 / 1.65$ & 2 & 2.849 \\
& 3 & 2.844 \\
& 1 & 2.977 \\
$0.99 / 2.33$ & 2 & 2.976 \\
& 3 & 2.972 \\
& & 3.136 \\
$0.999 / 3.10$ & 1 & 3.136 \\
& 2 & 3.133 \\
& 3 & 3.279 \\
$0.9999 / 3.72$ & 1 & 3.279 \\
& 2 & 3.277 \\
\hline
\end{tabular}


Table 9. Comparison of Objective Function between SIO with sensitivity analysis (1) and ASIO (2 and 3) Methods. Case 3.

\begin{tabular}{|c|c|c|}
\hline Prob. Surv./Saf. Index & Method & Obj. Function $\left(\mathrm{cm} \cdot{ }^{3 *} 10^{-5}\right)$ \\
\hline $0.5 / 0.0$ & $\begin{array}{l}1 \\
2 \\
3\end{array}$ & $\begin{array}{l}2.576 \\
2.576 \\
2.568\end{array}$ \\
\hline $0.84 / 1.0$ & $\begin{array}{l}1 \\
2 \\
3\end{array}$ & $\begin{array}{l}2.914 \\
2.913 \\
2.909\end{array}$ \\
\hline $0.9 / 1.28$ & $\begin{array}{l}1 \\
2 \\
3\end{array}$ & $\begin{array}{l}3.023 \\
3.023 \\
3.018\end{array}$ \\
\hline $0.95 / 1.65$ & $\begin{array}{l}1 \\
2 \\
3\end{array}$ & $\begin{array}{l}3.181 \\
3.181 \\
3.177\end{array}$ \\
\hline $0.99 / 2.33$ & $\begin{array}{l}1 \\
2 \\
3\end{array}$ & $\begin{array}{l}3.530 \\
3.530 \\
3.526\end{array}$ \\
\hline $0.999 / 3.10$ & $\begin{array}{c}1 \\
2 \\
3(4 \text { iter. })\end{array}$ & $\begin{array}{l}4.024 \\
4.024 \\
4.023\end{array}$ \\
\hline $0.9999 / 3.72$ & $\begin{array}{l}1 \\
2 \\
3\end{array}$ & $\begin{array}{l}4.516 \\
4.516 \\
4.514\end{array}$ \\
\hline
\end{tabular}


Table 10. Comparison of Objective Function between SIO with sensitivity analysis (1) and ASIO (2 and 3) Methods. Case 4.

\begin{tabular}{|c|c|c|}
\hline Prob. Surv./Saf. Index & Method & Obj. Function $\left(\mathrm{cm} .{ }^{3 *} 10^{-5}\right)$ \\
\hline $0.5 / 0.0$ & $\begin{array}{l}1 \\
2 \\
3\end{array}$ & $\begin{array}{l}2.576 \\
2.576 \\
2.569\end{array}$ \\
\hline $0.84 / 1.0$ & $\begin{array}{l}1 \\
2 \\
3\end{array}$ & $\begin{array}{l}3.115 \\
3.115 \\
3.110\end{array}$ \\
\hline $0.9 / 1.28$ & $\begin{array}{l}1 \\
2 \\
3\end{array}$ & $\begin{array}{l}3.309 \\
3.309 \\
3.305\end{array}$ \\
\hline $0.95 / 1.65$ & $\begin{array}{l}1 \\
2 \\
3\end{array}$ & $\begin{array}{l}3.615 \\
3.615 \\
3.594\end{array}$ \\
\hline $0.99 / 2.33$ & $\begin{array}{l}1 \\
2 \\
3\end{array}$ & $\begin{array}{l}4.325 \\
4.332 \\
4.324\end{array}$ \\
\hline $0.999 / 3.10$ & $\begin{array}{l}1 \\
2 \\
3\end{array}$ & $\begin{array}{l}5.486 \\
5.485 \\
5.423\end{array}$ \\
\hline $0.9999 / 3.72$ & $\begin{array}{c}1 \\
2 \\
3(4 \text { iter. })\end{array}$ & $\begin{array}{l}6.900 \\
6.899 \\
6.898\end{array}$ \\
\hline
\end{tabular}


Table 11. Comparison of Objective Function between SIO with sensitivity analysis (1) and ASIO (2 and 3) Methods. Case 5.

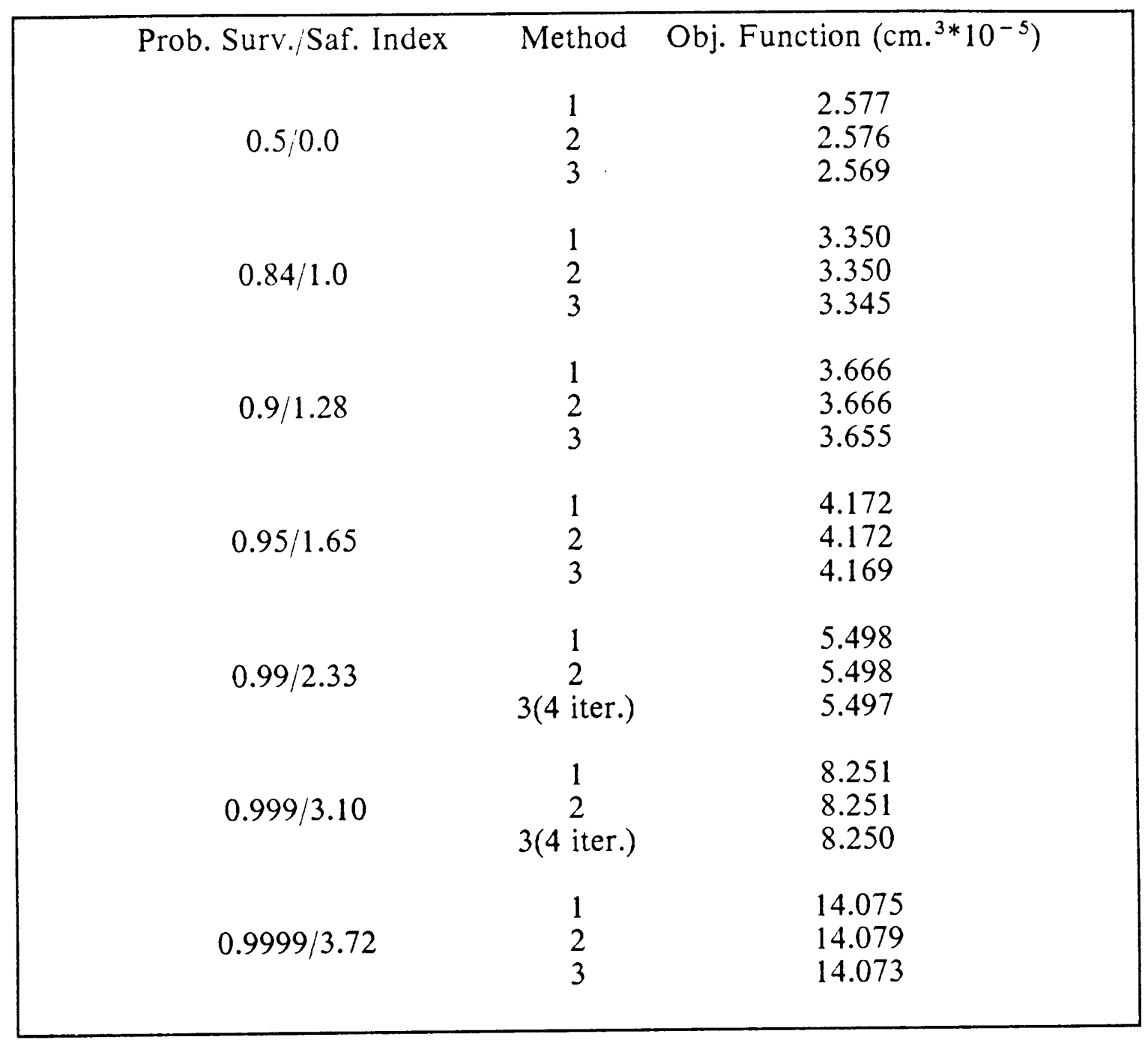


Table 12. Final design for SIO method for $\beta=2.33$ and initial design vector $2.0,3.0,5.0$.

\begin{tabular}{|ccccc|}
\hline & $\begin{array}{c}\text { Web Thick. } \\
(\mathrm{cm} .)\end{array}$ & $\begin{array}{c}\text { Fl. Thick. } \\
(\mathrm{cm} .)\end{array}$ & $\begin{array}{c}\text { Cable area } \\
\left(\mathrm{cm} .{ }^{2}\right)\end{array}$ & $\begin{array}{c}\text { Obj. Function } \\
\left(\mathrm{cm} .{ }^{3 *} 10^{-5}\right)\end{array}$ \\
Case 1 & 0.50928 & 8.088 & 36.30 & 2.649 \\
Case 2 & 0.5937 & 10.316 & 42.04 & 2.977 \\
Case 3 & 0.705 & 12.140 & 42.33 & 3.530 \\
Case 4 & 0.843 & 14.65 & 53.02 & 4.325 \\
Case 5 & 1.036 & 18.27 & 69.23 & 5.498 \\
\hline
\end{tabular}


Table 13. Final design for the First ASIO method for $\beta=2.33$ and initial design vector $1.0,1.5,2.5$.

\begin{tabular}{|lcccc|}
\hline & $\begin{array}{c}\text { Web Thick. } \\
(\mathrm{cm} .)\end{array}$ & $\begin{array}{c}\text { Fl. Thick. } \\
(\mathrm{cm} .)\end{array}$ & $\begin{array}{c}\text { Cable area } \\
\left(\mathrm{cm} .{ }^{2}\right)\end{array}$ & $\begin{array}{c}\text { Obj. Function } \\
\left(\mathrm{cm} .{ }^{3 *} 10^{-5}\right)\end{array}$ \\
Case 1 & 0.508 & 8.09 & 36.29 & 2.648 \\
Case 2 & 0.586 & 9.561 & 38.68 & 2.977 \\
Case 3 & 0.704 & 12.140 & 42.34 & 3.529 \\
Case 4 & 0.843 & 14.65 & 53.04 & 4.325 \\
Case 5 & 1.035 & 18.25 & 69.28 & 5.497 \\
\hline
\end{tabular}


Table 14. Final design for the First ASIO method for $\beta=2.33$ and initial design vector $4.0,6,0,10.0$.

\begin{tabular}{|ccccc|}
\hline & $\begin{array}{c}\text { Web Thick. } \\
(\mathrm{cm} .)\end{array}$ & $\begin{array}{c}\text { Fl. Thick. } \\
(\mathrm{cm} .)\end{array}$ & $\begin{array}{c}\text { Cable area } \\
\left(\mathrm{cm} .{ }^{2}\right)\end{array}$ & $\begin{array}{c}\text { Obj. Function } \\
\left(\mathrm{cm} .{ }^{3 *} 10^{-5}\right)\end{array}$ \\
Case 1 & 0.508 & 8.09 & 36.29 & 2.648 \\
Case 2 & 0.586 & 9.561 & 38.68 & 2.977 \\
Case 3 & 0.705 & 12.140 & 42.37 & 3.531 \\
Case 4 & 0.845 & 14.66 & 53.01 & 4.327 \\
Case 5 & 1.036 & 18.23 & 69.42 & 5.499 \\
\hline
\end{tabular}


Table 15. Final design for the Second ASIO method for $\beta=2.33$ and initial design vector $1.0,1.5,2.5$.

\begin{tabular}{|ccccc|}
\hline & $\begin{array}{c}\text { Web Thick. } \\
(\mathrm{cm} .)\end{array}$ & $\begin{array}{c}\text { Fl. Thick. } \\
(\mathrm{cm} .)\end{array}$ & $\begin{array}{c}\text { Cable area } \\
\left(\mathrm{cm} .{ }^{2}\right)\end{array}$ & $\begin{array}{c}\text { Obj. Function } \\
\left(\mathrm{cm} .{ }^{3 * 10^{-5}}\right)\end{array}$ \\
Case 1 & 0.508 & 8.09 & 36.30 & 2.648 \\
Case 2 & 0.581 & 9.567 & 38.67 & 2.977 \\
Case 3 & 0.698 & 12.12 & 42.34 & 3.525 \\
Case 4 & 0.845 & 14.66 & 53.01 & 4.321 \\
Case 5 & 1.034 & 18.27 & 69.20 & 5.497 \\
\hline
\end{tabular}


Table 16. Final design for the Second ASIO method for $\beta=2.33$ and initial design vector 4.0,6.0,10.0.

\begin{tabular}{|ccccc|}
\hline & $\begin{array}{c}\text { Web Thick. } \\
(\mathrm{cm} .)\end{array}$ & $\begin{array}{c}\text { Fl. Thick. } \\
(\mathrm{cm} .)\end{array}$ & $\begin{array}{c}\text { Cable area } \\
\left(\mathrm{cm} .{ }^{2}\right)\end{array}$ & $\begin{array}{c}\text { Obj. Function } \\
\left(\mathrm{cm} .{ }^{3 * 1} 10^{-5}\right)\end{array}$ \\
Case 1 & 0.419 & 8.064 & 36.29 & 2.618 \\
Case 2 & 0.472 & 9.644 & 38.66 & 2.955 \\
Case 3 & 0.569 & 12.27 & 42.21 & 3.511 \\
Case 4 & 0.788 & 14.72 & 52.94 & 4.315 \\
Case 5 & 1.034 & 18.30 & 69.03 & 5.497 \\
\hline
\end{tabular}


Table 17. Comparison of Computational Time between SIO with sensitivity analysis (1) and ASIO (2 and 3) Methods. Case 1.

\begin{tabular}{|c|c|c|}
\hline Prob. Surv./Saf. Index & Method & CPU Time (Sec. $\left.{ }^{*} 100\right)$ \\
\hline $0.5 / 0.0$ & $\begin{array}{l}1 \\
2 \\
3(4 \text { iter. })\end{array}$ & $\begin{array}{l}70 \\
34 \\
47\end{array}$ \\
\hline $0.84 / 1.0$ & $\begin{array}{l}1 \\
2 \\
3\end{array}$ & $\begin{array}{l}59 \\
33 \\
37\end{array}$ \\
\hline $0.9 / 1.28$ & $\begin{array}{l}1 \\
2 \\
3\end{array}$ & $\begin{array}{l}59 \\
33 \\
37\end{array}$ \\
\hline $0.95 / 1.65$ & $\begin{array}{l}1 \\
2 \\
3\end{array}$ & $\begin{array}{l}59 \\
32 \\
39\end{array}$ \\
\hline $0.99 / 2.33$ & $\begin{array}{l}1 \\
2 \\
3\end{array}$ & $\begin{array}{l}59 \\
33 \\
39\end{array}$ \\
\hline $0.999 / 3.10$ & $\begin{array}{l}1 \\
2 \\
3\end{array}$ & $\begin{array}{l}59 \\
32 \\
38\end{array}$ \\
\hline $0.9999 / 3.72$ & $\begin{array}{l}1 \\
2 \\
3\end{array}$ & $\begin{array}{l}60 \\
42 \\
39\end{array}$ \\
\hline
\end{tabular}


Table 18. Comparison of Computational Time between SIO with sensitivity analysis (1) and ASIO (2 and 3) Methods. Case 2.

\begin{tabular}{|c|c|c|}
\hline Prob. Surv./Saf. Index & Method & CPU Time (Sec. $\left.{ }^{*} 100\right)$ \\
\hline $0.5 / 0.0$ & $\begin{array}{l}1 \\
2 \\
3\end{array}$ & $\begin{array}{l}55 \\
30 \\
30\end{array}$ \\
\hline $0.84 / 1.0$ & $\begin{array}{l}1 \\
2 \\
3\end{array}$ & $\begin{array}{l}56 \\
30 \\
30\end{array}$ \\
\hline $0.9 / 1.28$ & $\begin{array}{l}1 \\
2 \\
3\end{array}$ & $\begin{array}{l}56 \\
31 \\
30\end{array}$ \\
\hline $0.95 / 1.65$ & $\begin{array}{l}1 \\
2 \\
3\end{array}$ & $\begin{array}{l}56 \\
32 \\
29\end{array}$ \\
\hline $0.99 / 2.33$ & $\begin{array}{l}1 \\
2 \\
3\end{array}$ & $\begin{array}{l}58 \\
32 \\
30\end{array}$ \\
\hline $0.999 / 3.10$ & $\begin{array}{l}1 \\
2 \\
3\end{array}$ & $\begin{array}{l}59 \\
39 \\
31\end{array}$ \\
\hline $0.9999 / 3.72$ & $\begin{array}{l}1 \\
2 \\
3\end{array}$ & $\begin{array}{l}59 \\
32 \\
31\end{array}$ \\
\hline
\end{tabular}


Table 19. Comparison of Computational Time between SIO with sensitivity analysis (1) and ASIO (2 and 3) Methods. Case 3.

Prob. Surv./Saf. Index

$0.5 / 0.0$

$0.84 / 1.0$

$0.9 / 1.28$

$0.95 / 1.65$

$0.99 / 2.33$

$0.999 / 3.10$

$0.9999 / 3.72$

$\begin{array}{cc}\text { Method } & \left.\text { CPU Time (Sec. }{ }^{*} 100\right) \\ 1 & 57 \\ 2 & 27 \\ 3 & 31 \\ & \\ 1 & 58 \\ 2 & 29 \\ 3 & 30 \\ 1 & \\ 2 & 59 \\ 3 & 31 \\ & 32 \\ 1 & \\ 2 & 60 \\ 3 & 31 \\ & 32 \\ 1 & \\ 2 & 59 \\ 3 & 32 \\ 1 & 30 \\ 2 & \\ 3(4 \text { iter.) } & 58 \\ 1 & 35 \\ 2 & 34 \\ 3 & 50 \\ & 25 \\ & 28\end{array}$


Table 20. Comparison of Computational Time between SIO with sensitivity analysis (1) and ASIO (2 and 3) Methods. Case 4.

Prob. Surv./Saf. Index

$0.5 / 0.0$

$0.84 / 1.0$

$0.9 / 1.28$

$0.95 / 1.65$

$0.99 / 2.33$

$0.999 / 3.10$

$0.9999 / 3.72$
Method

CPU Time (Sec. $\left.{ }^{*} 100\right)$

1

2

54

27

29

58

30

31

58

30

31

54

35

30

53

45

27

65

47

38

71

32

44 
Table 21. Comparison of Computational Time between SIO with sensitivity analysis (1) and ASIO (2 and 3) Methods. Case 5.

\begin{tabular}{|c|c|c|}
\hline Prob. Surv./Saf. Index & Method & CPU Time (Sec. $\left.{ }^{*} 100\right)$ \\
\hline $0.5 / 0.0$ & $\begin{array}{l}1 \\
2 \\
3\end{array}$ & $\begin{array}{l}54 \\
25 \\
29\end{array}$ \\
\hline $0.84 / 1.0$ & $\begin{array}{l}1 \\
2 \\
3\end{array}$ & $\begin{array}{l}54 \\
29 \\
30\end{array}$ \\
\hline $0.9 / 1.28$ & $\begin{array}{l}1 \\
2 \\
3\end{array}$ & $\begin{array}{l}56 \\
31 \\
31\end{array}$ \\
\hline $0.95 / 1.65$ & $\begin{array}{l}1 \\
2 \\
3\end{array}$ & $\begin{array}{l}56 \\
42 \\
29\end{array}$ \\
\hline $0.99 / 2.33$ & $\begin{array}{l}1 \\
2 \\
3(4 \text { iter. })\end{array}$ & $\begin{array}{l}65 \\
45 \\
40\end{array}$ \\
\hline $0.999 / 3.10$ & $\begin{array}{l}1 \\
2 \\
3(4 \text { 1ter. })\end{array}$ & $\begin{array}{l}91 \\
49 \\
59\end{array}$ \\
\hline $0.9999 / 3.72$ & $\begin{array}{l}1 \\
2 \\
3\end{array}$ & $\begin{array}{l}60 \\
42 \\
34\end{array}$ \\
\hline
\end{tabular}


Table 22. Computational time breakdown for $\beta=2.33$ for SIO (1), SIO with sensitivity analysis (2) and ASIO (3 and 4) methods.

\begin{tabular}{|c|c|c|c|c|}
\hline & Method & No. O.D.M. & $\begin{array}{l}\text { O.D.M. Time } \\
\left(\text { Sec. }^{*} 100\right)\end{array}$ & $\begin{array}{l}\text { Dir. Search Time } \\
\left(\text { Sec. }^{*} 100\right)\end{array}$ \\
\hline Case 1 & $\begin{array}{l}1 \\
2 \\
3 \\
4\end{array}$ & $\begin{array}{l}24 \\
24 \\
24 \\
25\end{array}$ & $\begin{array}{l}23 \\
55 \\
27 \\
34\end{array}$ & $\begin{array}{r}41 \\
1 \\
1 \\
2\end{array}$ \\
\hline Case 2 & $\begin{array}{l}1 \\
2 \\
3 \\
4\end{array}$ & $\begin{array}{l}25 \\
25 \\
28 \\
25\end{array}$ & $\begin{array}{l}28 \\
54 \\
25 \\
27\end{array}$ & $\begin{array}{c}58 \\
1 \\
1 \\
1\end{array}$ \\
\hline Case 3 & $\begin{array}{l}1 \\
2 \\
3 \\
4\end{array}$ & $\begin{array}{l}24 \\
25 \\
28 \\
25\end{array}$ & $\begin{array}{l}40 \\
57 \\
26 \\
24\end{array}$ & $\begin{array}{c}49 \\
0 \\
3 \\
1\end{array}$ \\
\hline Case 4 & $\begin{array}{l}1 \\
2 \\
3 \\
4\end{array}$ & $\begin{array}{l}24 \\
23 \\
25 \\
20\end{array}$ & $\begin{array}{l}34 \\
50 \\
43 \\
21\end{array}$ & $\begin{array}{r}61 \\
0 \\
0 \\
0\end{array}$ \\
\hline Case 5 & $\begin{array}{l}1 \\
2 \\
3 \\
4\end{array}$ & $\begin{array}{l}29 \\
26 \\
30 \\
26\end{array}$ & $\begin{array}{l}43 \\
62 \\
41 \\
34\end{array}$ & $\begin{array}{r}80 \\
1 \\
2 \\
0\end{array}$ \\
\hline
\end{tabular}


Table 23. Number of analyses required for $\beta=2.33$ for SIO (1), SIO with sensitivity analysis (2) and ASIO (3 and 4) methods.

\begin{tabular}{|c|c|c|c|c|}
\hline & Method & $\begin{array}{l}\text { App. Obj. Fun. } \\
\text { Evaluations }\end{array}$ & $\begin{array}{l}\text { Constraint } \\
\text { Evaluations }\end{array}$ & $\begin{array}{l}\text { App. Con. Fun. } \\
\text { Evaluations }\end{array}$ \\
\hline Case 1 & $\begin{array}{l}1 \\
2 \\
3 \\
4\end{array}$ & $\begin{array}{l}248 \\
251 \\
284 \\
257\end{array}$ & $\begin{array}{r}144 \\
49 \\
63 \\
52\end{array}$ & $\begin{array}{l}201 \\
203 \\
223 \\
207\end{array}$ \\
\hline Case 2 & $\begin{array}{l}1 \\
2 \\
3 \\
4\end{array}$ & $\begin{array}{l}250 \\
244 \\
302 \\
251\end{array}$ & $\begin{array}{r}151 \\
51 \\
69 \\
52\end{array}$ & $\begin{array}{l}200 \\
194 \\
235 \\
201\end{array}$ \\
\hline Case 3 & $\begin{array}{l}1 \\
2 \\
3 \\
4\end{array}$ & $\begin{array}{l}254 \\
253 \\
326 \\
250\end{array}$ & $\begin{array}{r}145 \\
51 \\
78 \\
50\end{array}$ & $\begin{array}{l}206 \\
203 \\
250 \\
202\end{array}$ \\
\hline Case 4 & $\begin{array}{l}1 \\
2 \\
3 \\
4\end{array}$ & $\begin{array}{l}254 \\
232 \\
394 \\
217\end{array}$ & $\begin{array}{r}145 \\
47 \\
127 \\
52\end{array}$ & $\begin{array}{l}206 \\
186 \\
269 \\
177\end{array}$ \\
\hline Case 5 & $\begin{array}{l}1 \\
2 \\
3 \\
4\end{array}$ & $\begin{array}{l}341 \\
310 \\
425 \\
314\end{array}$ & $\begin{array}{r}175 \\
53 \\
108 \\
54\end{array}$ & $\begin{array}{l}283 \\
258 \\
319 \\
262\end{array}$ \\
\hline
\end{tabular}


Table 24. Comparison of Objective Function between original SIO (Method 1) and ASIO (Methods 2 and 3). Case 1 .

\begin{tabular}{|lcc|}
\hline Prob. Surv./Saf. Index & Method & Obj. Function $\left(\mathrm{cm}^{3 *} 10^{-5}\right)$ \\
& 1 & 2.576 \\
$0.5 / 0.0$ & 2 & 2.575 \\
& 3 & 2.575 \\
$0.84 / 1.0$ & 1 & 2.607 \\
& 2 & 2.607 \\
& 3 & 2.591 \\
$0.9 / 1.28$ & 1 & 2.616 \\
& 2 & 2.616 \\
& 3 & 2.600 \\
$0.95 / 1.65$ & 1 & 2.628 \\
& 2 & 2.628 \\
& 3 & 2.617 \\
$0.99 / 2.33$ & 1 & 2.649 \\
& 2 & 2.649 \\
& 3 & 2.634 \\
$0.999 / 3.10$ & 1 & 2.674 \\
& 2 & 2.674 \\
& 3 & 2.659 \\
$0.9999 / 3.72$ & 1 & 2.694 \\
& 2 & 2.694 \\
& 3 & 2.680 \\
\hline
\end{tabular}


Table 25. Comparison of Objective Function between original SIO (Method 1) and ASIO (Methods 2 and 3). Case 2.

\begin{tabular}{|c|c|c|}
\hline Prob. Surv./Saf. Index & Method & Obj. Function $\left(\mathrm{cm} .{ }^{3 *} 10^{-5}\right)$ \\
\hline $0.5 / 0.0$ & $\begin{array}{l}1 \\
2 \\
3\end{array}$ & $\begin{array}{l}2.576 \\
2.576 \\
2.563\end{array}$ \\
\hline $0.84 / 1.0$ & $\begin{array}{l}1 \\
2 \\
3\end{array}$ & $\begin{array}{l}2.736 \\
2.736 \\
2.726\end{array}$ \\
\hline $0.9 / 1.28$ & $\begin{array}{l}1 \\
2 \\
3\end{array}$ & $\begin{array}{l}2.783 \\
2.783 \\
2.774\end{array}$ \\
\hline $0.95 / 1.65$ & $\begin{array}{l}1 \\
2 \\
3\end{array}$ & $\begin{array}{l}2.849 \\
2.849 \\
2.840\end{array}$ \\
\hline $0.99 / 2.33$ & $\begin{array}{l}1 \\
2 \\
3\end{array}$ & $\begin{array}{l}2.977 \\
2.977 \\
2.969\end{array}$ \\
\hline $0.999 / 3.10$ & $\begin{array}{l}1 \\
2 \\
3\end{array}$ & $\begin{array}{l}3.136 \\
3.136 \\
3.123\end{array}$ \\
\hline $0.9999 / 3.72$ & $\begin{array}{l}1 \\
2 \\
3\end{array}$ & $\begin{array}{l}3.279 \\
3.279 \\
3.274\end{array}$ \\
\hline
\end{tabular}


Table 26. Comparison of Objective Function between original SIO (Method 1) and ASIO (Methods 2 and 3). Case 3.

\begin{tabular}{|c|c|c|}
\hline Prob. Surv./Saf. Index & Method & Obj. Function $\left(\mathrm{cm} \cdot{ }^{3 *} 10^{-5}\right)$ \\
\hline $0.5 / 0.0$ & $\begin{array}{l}1 \\
2 \\
3\end{array}$ & $\begin{array}{l}2.576 \\
2.576 \\
2.565\end{array}$ \\
\hline $0.84 / 1.0$ & $\begin{array}{l}1 \\
2 \\
3\end{array}$ & $\begin{array}{l}2.914 \\
2.914 \\
2.906\end{array}$ \\
\hline $0.9 / 1.28$ & $\begin{array}{l}1 \\
2 \\
3\end{array}$ & $\begin{array}{l}3.023 \\
3.023 \\
3.016\end{array}$ \\
\hline $0.95 / 1.65$ & $\begin{array}{l}1 \\
2 \\
3\end{array}$ & $\begin{array}{l}3.181 \\
3.181 \\
3.175\end{array}$ \\
\hline $0.99 / 2.33$ & $\begin{array}{l}1 \\
2 \\
3\end{array}$ & $\begin{array}{l}3.530 \\
3.530 \\
3.524\end{array}$ \\
\hline $0.999 / 3.10$ & $\begin{array}{l}1 \\
2 \\
3\end{array}$ & $\begin{array}{l}4.020 \\
4.021 \\
\text { no conv. }\end{array}$ \\
\hline $0.9999 / 3.72$ & $\begin{array}{l}1 \\
2 \\
3\end{array}$ & $\begin{array}{l}4.516 \\
4.512 \\
\text { no conv. }\end{array}$ \\
\hline
\end{tabular}


Table 27. Comparison of Objective Function between original SIO (Method 1) and ASIO (Methods 2 and 3). Case 4.

\begin{tabular}{|c|c|c|}
\hline Prob. Surv./Saf. Index & Method & Obj. Function $\left(\mathrm{cm} \cdot{ }^{3 *} 10^{-5}\right)$ \\
\hline $0.5 / 0.0$ & $\begin{array}{l}1 \\
2 \\
3\end{array}$ & $\begin{array}{l}2.576 \\
2.576 \\
2.560\end{array}$ \\
\hline $0.84 / 1.0$ & $\begin{array}{l}1 \\
2 \\
3\end{array}$ & $\begin{array}{l}3.115 \\
3.114 \\
3.108\end{array}$ \\
\hline $0.9 / 1.28$ & $\begin{array}{l}1 \\
2 \\
3\end{array}$ & $\begin{array}{l}3.309 \\
3.309 \\
3.303\end{array}$ \\
\hline $0.95 / 1.65$ & $\begin{array}{l}1 \\
2 \\
3\end{array}$ & $\begin{array}{l}3.615 \\
3.612 \\
3.598\end{array}$ \\
\hline $0.99 / 2.33$ & $\begin{array}{l}1 \\
2 \\
3\end{array}$ & $\begin{array}{l}4.326 \\
4.327 \\
\text { no conv. }\end{array}$ \\
\hline $0.999 / 3.10$ & $\begin{array}{l}1 \\
2 \\
3\end{array}$ & $\begin{array}{l}5.486 \\
5.480 \\
\text { no conv. }\end{array}$ \\
\hline $0.9999 / 3.72$ & $\begin{array}{l}1 \\
2 \\
3\end{array}$ & $\begin{array}{l}6.900 \\
6.900 \\
\text { no conv. }\end{array}$ \\
\hline
\end{tabular}


Table 28. Comparison of Objective Function between original SIO (Method 1) and ASIO (Methods 2 and 3). Case 5.

\begin{tabular}{|c|c|c|}
\hline Prob. Surv./Saf. Index & Method & Obj. Function $\left(\mathrm{cm} \cdot{ }^{3 *} 10^{-5}\right)$ \\
\hline $0.5 / 0.0$ & $\begin{array}{l}1 \\
2 \\
3\end{array}$ & $\begin{array}{l}2.577 \\
2.576 \\
2.567\end{array}$ \\
\hline $0.84 / 1.0$ & $\begin{array}{l}1 \\
2 \\
3\end{array}$ & $\begin{array}{l}3.350 \\
3.347 \\
3.331\end{array}$ \\
\hline $0.9 / 1.28$ & $\begin{array}{l}1 \\
2 \\
3\end{array}$ & $\begin{array}{l}3.666 \\
3.664 \\
3.627\end{array}$ \\
\hline $0.95 / 1.65$ & $\begin{array}{l}1 \\
2 \\
3\end{array}$ & $\begin{array}{l}4.172 \\
4.173 \\
\text { no conv. }\end{array}$ \\
\hline $0.99 / 2.33$ & $\begin{array}{l}1 \\
2 \\
3\end{array}$ & $\begin{array}{l}5.498 \\
5.492 \\
\text { no conv. }\end{array}$ \\
\hline $0.999 / 3.10$ & $\begin{array}{l}1 \\
2 \\
3\end{array}$ & $\begin{array}{l}8.252 \\
8.252 \\
\text { no conv. }\end{array}$ \\
\hline $0.9999 / 3.72$ & $\begin{array}{l}1 \\
2 \\
3\end{array}$ & $\begin{array}{l}14.076 \\
14.079 \\
\text { no conv. }\end{array}$ \\
\hline
\end{tabular}


Table 29. Comparison of Computational Time between SIO with sensitivity analysis (Method 1) and ASIO (Methods 2 and 3). Case 1.

\begin{tabular}{|c|c|c|}
\hline Prob. Surv./Saf. Index & Method & CPU Time (Sec. $\left.{ }^{*} 100\right)$ \\
\hline $0.5 / 0.0$ & $\begin{array}{l}1 \\
2 \\
3\end{array}$ & $\begin{array}{l}50 \\
14 \\
12\end{array}$ \\
\hline $0.84 / 1.0$ & $\begin{array}{l}1 \\
2 \\
3\end{array}$ & $\begin{array}{l}53 \\
18 \\
17\end{array}$ \\
\hline $0.9 / 1.28$ & $\begin{array}{l}1 \\
2 \\
3\end{array}$ & $\begin{array}{l}52 \\
18 \\
17\end{array}$ \\
\hline $0.95 / 1.65$ & $\begin{array}{l}1 \\
2 \\
3\end{array}$ & $\begin{array}{l}53 \\
18 \\
17\end{array}$ \\
\hline $0.99 / 2.33$ & $\begin{array}{l}1 \\
2 \\
3\end{array}$ & $\begin{array}{l}53 \\
18 \\
17\end{array}$ \\
\hline $0.999 / 3.10$ & $\begin{array}{l}1 \\
2 \\
3\end{array}$ & $\begin{array}{l}53 \\
19 \\
17\end{array}$ \\
\hline $0.9999 / 3.72$ & $\begin{array}{l}1 \\
2 \\
3\end{array}$ & $\begin{array}{l}54 \\
19 \\
17\end{array}$ \\
\hline
\end{tabular}


Table 30. Comparison of Computational Time between SIO with sensitivity analysis (Method 1) and ASIO (Methods 2 and 3). Case 2.

\begin{tabular}{|c|c|c|}
\hline Prob. Surv./Saf. Index & Method & CPU Time (Sec. $\left.{ }^{*} 100\right)$ \\
\hline $0.5 / 0.0$ & $\begin{array}{l}1 \\
2 \\
3\end{array}$ & $\begin{array}{l}54 \\
18 \\
16\end{array}$ \\
\hline $0.84 / 1.0$ & $\begin{array}{l}1 \\
2 \\
3\end{array}$ & $\begin{array}{l}55 \\
20 \\
15\end{array}$ \\
\hline $0.9 / 1.28$ & $\begin{array}{l}1 \\
2 \\
3\end{array}$ & $\begin{array}{l}55 \\
20 \\
15\end{array}$ \\
\hline $0.95 / 1.65$ & $\begin{array}{l}1 \\
2 \\
3\end{array}$ & $\begin{array}{l}55 \\
19 \\
15\end{array}$ \\
\hline $0.99 / 2.33$ & $\begin{array}{l}1 \\
2 \\
3\end{array}$ & $\begin{array}{l}51 \\
21 \\
14\end{array}$ \\
\hline $0.999 / 3.10$ & $\begin{array}{l}1 \\
2 \\
3\end{array}$ & $\begin{array}{l}49 \\
22 \\
15\end{array}$ \\
\hline 0.999233 .72 & $\begin{array}{l}1 \\
2 \\
3\end{array}$ & $\begin{array}{l}48 \\
23 \\
15\end{array}$ \\
\hline
\end{tabular}


Table 31. Comparison of Computational Time between SIO with sensitivity analysis (Method 1) and ASIO (Methods 2 and 3). Case 3.

\begin{tabular}{|c|c|c|}
\hline Prob. Surv./Saf. Index & Method & CPU Time (Sec. $\left.{ }^{*} 100\right)$ \\
\hline $0.5 / 0.0$ & $\begin{array}{l}1 \\
2 \\
3\end{array}$ & $\begin{array}{l}52 \\
18 \\
15\end{array}$ \\
\hline $0.84 / 1.0$ & $\begin{array}{l}1 \\
2 \\
3\end{array}$ & $\begin{array}{l}53 \\
20 \\
15\end{array}$ \\
\hline $0.9 / 1.28$ & $\begin{array}{l}1 \\
2 \\
3\end{array}$ & $\begin{array}{l}54 \\
20 \\
15\end{array}$ \\
\hline $0.95 / 1.65$ & $\begin{array}{l}1 \\
2 \\
3\end{array}$ & $\begin{array}{l}56 \\
22 \\
15\end{array}$ \\
\hline $0.99 / 2.33$ & $\begin{array}{l}1 \\
2 \\
3\end{array}$ & $\begin{array}{l}55 \\
24 \\
14\end{array}$ \\
\hline $0.999 / 3.10$ & $\begin{array}{l}1 \\
2 \\
3\end{array}$ & $\begin{array}{l}62 \\
30 \\
--\end{array}$ \\
\hline $0.9999 / 3.72$ & $\begin{array}{l}1 \\
2 \\
3\end{array}$ & $\begin{array}{l}52 \\
44 \\
--\end{array}$ \\
\hline
\end{tabular}


Table 32. Comparison of Computational Time between SIO with sensitivity analysis (Method 1) and ASIO (Methods 2 and 3). Case 4.

\begin{tabular}{|c|c|c|}
\hline Prob. Surv./Saf. Index & Method & CPU Time (Sec. * 100) \\
\hline $0.5 / 0.0$ & $\begin{array}{l}1 \\
2 \\
3\end{array}$ & $\begin{array}{l}52 \\
21 \\
15\end{array}$ \\
\hline $0.84 / 1.0$ & $\begin{array}{l}1 \\
2 \\
3\end{array}$ & $\begin{array}{l}53 \\
19 \\
15\end{array}$ \\
\hline $0.9 / 1.28$ & $\begin{array}{l}1 \\
2 \\
3\end{array}$ & $\begin{array}{l}52 \\
19 \\
14\end{array}$ \\
\hline $0.95 / 1.65$ & $\begin{array}{l}1 \\
2 \\
3\end{array}$ & $\begin{array}{l}54 \\
24 \\
16\end{array}$ \\
\hline $0.99 / 2.33$ & $\begin{array}{l}1 \\
2 \\
3\end{array}$ & $\begin{array}{l}46 \\
21 \\
--\end{array}$ \\
\hline $0.999 / 3.10$ & $\begin{array}{l}1 \\
2 \\
3\end{array}$ & $\begin{array}{l}57 \\
23 \\
--\end{array}$ \\
\hline $0.9999 / 3.72$ & $\begin{array}{l}1 \\
2 \\
3\end{array}$ & $\begin{array}{l}71 \\
31 \\
--\end{array}$ \\
\hline
\end{tabular}


Table 33. Comparison of Computational Time between SIO with sensitivity analysis (Method 1) and ASIO (Methods 2 and 3). Case 5.

\begin{tabular}{|ccc|}
\hline Prob. Surv./Saf. Index & Method & CPU Time (Sec. ${ }^{*}$ 100) \\
& 1 & 49 \\
$0.5 / 0.0$ & 2 & 18 \\
& 3 & 14 \\
$0.84 / 1.0$ & 1 & 54 \\
& 2 & 25 \\
& 3 & 19 \\
$0.9 / 1.28$ & 1 & 56 \\
& 2 & 30 \\
& 3 & 14 \\
$0.95 / 1.65$ & 1 & 54 \\
& 2 & 23 \\
& 3 & -- \\
$0.99 / 2.33$ & 1 & 63 \\
& 2 & 36 \\
& 3 & -- \\
$0.999 / 3.10$ & 1 & 72 \\
& 2 & 33 \\
& & -- \\
$0.9999 / 3.72$ & 1 & 75 \\
& 3 & 30 \\
& & -- \\
\hline
\end{tabular}




\section{The vita has been removed from the scanned document}

